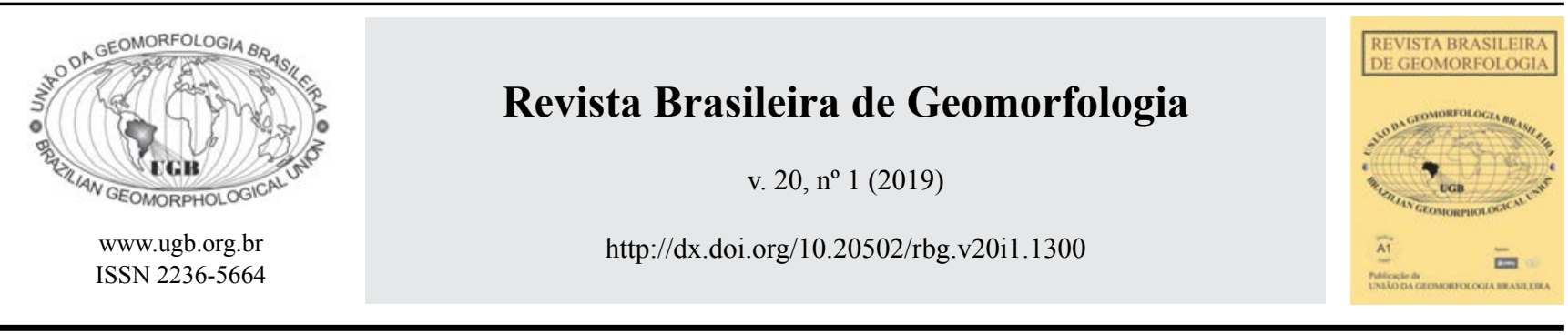

\title{
RELEVO DO CHAPADÃO DO DIAMANTE, SERRA DA CANASTRA/MG, BRASIL: COMPARTIMENTAÇÃO E ANÁLISE A PARTIR DOS ASPECTOS GEOMORFOMÉTRICOS
}

\author{
LANDFORMS OF CHAPADÃO DO DIAMANTE, SERRA DA \\ CANASTRA/MG, BRAZIL: SUBDIVISION AND ANALYSIS FROM THE \\ GEOMORPHOMETRIC ASPECTS
}

\author{
Thallita Isabela Silva Martins Nazar \\ Instituto de Geografia, Universidade Federal de Uberlândia \\ Av. João Naves de Ávila, 2121, Uberlândia, Minas Gerais. CEP: 38408-144. Brasil \\ E-mail: thallitamartins09@gmail.com
}

Silvio Carlos Rodrigues

Instituto de Geografia, Universidade Federal de Uberlândia

Av. João Naves de Ávila, 2121, Uberlândia, Minas Gerais. CEP: 38408-144. Brasil

E-mail:silgel@ufu.br

\author{
Informações sobre o Artigo \\ Recebido (Received): \\ 03/07/2018 \\ Aceito (Accepted): \\ 26/09/2018
}

Palavras-chave:

Geomorfometria; Mapa de Padrões de Relevo; Serra da Canastra.

\section{Keywords:}

Geomorphometry; Landform

Map; Serra da Canastra.

\section{Resumo:}

O Chapadão do Diamante $(\mathrm{ChD})$ faz parte da Serra da Canastra, localizada na região sudoeste do Estado de Minas Gerais (Brasil). É uma área de grande beleza cênica, considerada um monumento geomorfológico de grande exuberância. Aárea de estudo está localizada dentro de uma unidade de proteção, o Parque Nacional da Serra da Canastra. O principal objetivo deste trabalho foi classificar as formas de relevo do ChD, usando um Modelo Digital de Terreno Hidrologicamente Consistente. A metodologia é baseada nos pressupostos taxonômicos de Ross (1992), realizada por meio de análise geomorfométrica e mapeamento semiautomatizado, que considera três aspectos principais para a caracterização do relevo: Densidade de Drenagem, Índice de Concentração de Rugosidade e Densidade Topográfica, na escala de apresentação 1: 50.000. Os resultados demonstram uma riqueza de formas de relevo no $\mathrm{ChD}$, que vão desde topos aplanados e relevos dissecados a cristas de quartzito, marcadas por numerosos afloramentos rochosos nos setores leste e sul da área de estudo. Os resultados apresentados mostram uma subdivisão do relevo (Mapa de Padrões de Relevo), que pode preencher a lacuna de conhecimento em relação à distribuição e diversidade de formas de relevo no $\mathrm{ChD}$, na escala proposta. Esta contribuição subsidiará a pesquisa geomorfológica na área, tanto no estudo de processos e dinâmicas, como na origem e evolução da paisagem geomorfológica.

\section{Abstract:}

The Chapadão do Diamante $(\mathrm{ChD})$ is part of the Serra da Canastra, located in the southwest region of Minas Gerais State (Brazil). It is an area of great scenic 
beauty, considered a geomorphological monument of great exuberance. The study area is located inside a protection unit, the Serra da Canastra National Park. The main goal of this work was to classify the landforms of ChD, using a Hydrologically Consistent Digital Terrain Model. The methodology is based on Ross's (1992) taxonomy assumptions, realized through geomorphometric analysis and semi-automated mapping which considers three main aspects for the landform characterization: Drainage Density, Roughness Concentration Index and Topographic Density, at the presentation scale 1:50.000. The results demonstrate a wealth of ChD landforms, ranging from flat tops and dissected reliefs, to quartzite ridges, marked of numerous rocky outcrops in the eastern and southern sectors of the study area. The presented results shows a subdivision of the landforms (Landform Map), which can fill the knowledge gap regarding the distribution and diversity of landforms in $\mathrm{ChD}$, at the proposed scale. This contribution will subsidize the geomorphological research in the area, both in terms of the study of processes and dynamics, as well as the origin and evolution of the geomorphological landscape.

\section{Introdução}

A compartimentação do relevo, enquanto parte da cartografia geomorfológica, tem sido, atualmente, amparada pela modelagem digital da superfície terrestre, associada, em especial, aos Modelos Digitais de Elevação ou do Terreno (MDE/MDT) e à análise geomorfométrica, o que elevou a qualidade e eficiência dos mapeamentos dos fatos e fenômenos geomorfológicos. Os Sistemas de Informação Geográfica (SIG) contribuem para a dinamização de tal processo, pois permitem a realização de análises espaciais complexas e, conforme Rosa e Brito (1996), oferecem possibilidades de integração de dados obtidos por sensores remotos com diversos outros tipos de informações (laboratoriais, mapeamentos, levantamentos de campo, etc.), permitindo a sua aplicação nos mais variados campos das ciências da natureza.

No caso da Geomorfologia que é, por essência, uma ciência integradora de diferentes aspectos do meio físico, tais como geológicos, climáticos e hidrológicos, além dos materiais superficiais (SILVA; RODRIGUES, 2009); a aplicação de um SIG torna-se viável e recomendada. É válido salientar que o papel do SIG e dos produtos digitais que representam a superfície terrestre, MDE ou MDT, por exemplo, são ferramentas que visam contribuir com a análise geomorfológica, a qual deve se aliar sempre às pesquisas de campo, como levantamentos e anotações in situ, tanto pré quanto pós-mapeamento.

A Geomorfologia é uma ciência que possui bases teóricas consolidadas quando diz respeito à metodologia científica, mas que permite a associação de métodos e técnicas diferenciadas para o seu avanço, sendo a cartografia geomorfológica uma importante ferramenta para nortear e sintetizar a pesquisa nesta área do conhecimento (TRICART, 1965; ROSS, 2007). A representação do relevo é de grande importância à medida em que a análise espacial dos fatos geomórficos indica a gênese da paisagem, interdependências de processos e correlações entre a forma do relevo, o substrato, o clima e o material superficial (ROSS, 1992), mesmo que todos esses aspectos não sejam representados em um único mapa, mas em uma série de mapas correlacionáveis.

Destaca-se, portanto, o estudo morfológico pautado na identificação dos parâmetros geomorfométricos, sendo a altitude, declividade, curvatura e aspecto, os principais atributos topográficos utilizados (OLAYA, 2009; BISHOP; MINASNY, 2006). Nesse sentido, o MDE/MDT fornece subsídios importantes para esse tipo de estudo, pois, a partir do seu processamento, é possível obter uma descrição quantitativa do relevo (MACMILLAN, SHARY, 2009; CAMIZ, POSCOLIERI, 2015). Esta abordagem pode complementar as propostas de mapeamentos tradicionais do relevo, dentre as quais cita-se, a nível brasileiro, o Projeto RadamBrasil (RADAMBRASIL, 1983), a hierarquização do relevo de Ross (1992), e os sistemas de Relevo do IPT Instituto de Pesquisas Tecnológicas do Estado de São Paulo (PONÇANO, 1979), que por muito tempo foram aplicados manualmente, com considerável grau de abstração e preponderância de informações qualitativas.

Cabe à geomorfometria, de acordo com MacMillan e Shary (2009), a análise quantitativa diretamente relacionada à superfície da Terra. Pike, Evans e Hengl (2009) a definem como a ciência da quantificação topográfica, cujo foco operacional está na extração de parâmetros da superfície terrestre a partir de um MDE, sendo este a entrada primária da análise geomorfométrica. Evans (2012) relaciona o mapeamento geomorfológico à geomorfometria no 
sentido de que ambos possuem uma dependência comum na definição e delimitação de padrões de formas de relevo, considerando a diminuição de abstrações na sua interpretação.

Diante do exposto, é relevante destacar que inúmeros autores apresentam resultados de mapeamentos geomorfológicos com base na análise geomorfométrica, a partir da utilização de dados derivados de MDE ou MDT, bem como do uso de plataformas de SIG, corroborando para o desenvolvimento das pesquisas neste âmbito. Assim, pode-se citar Carneiro e Souza (2003); Gustavsson (2006); Santos et al. (2006); Evans, Hengl e Gorsevski (2009); Grecu (2009); Pavlopoulos, Evelpidou e Vassilopoulos (2009); Silva e Rodrigues (2009; 2010); Augustin, Fonseca e Rocha (2011); Fonseca; Zêzere e Neves (2015); Martins e Rodrigues (2016); Sena-Souza et al.(2016); Silveira, R. M. P.; Silveira C. T. (2016); Diniz et al.(2017).

$\mathrm{Na}$ literatura recente, observa-se uma lacuna de conhecimento detalhado ou semidetalhado (escalas maiores que $1: 100.000$ ) a respeito da dinâmica geomorfológica do Chapadão do Diamante $(\mathrm{ChD})$, Serra da Canastra (MG), o mesmo ocorrendo com a abordagem geológica. Além de pertencer ao Parque Nacional da Serra da Canastra (PARNA Canastra), unidade de conservação de proteção integral, criada em 1972 (MMA/IBAMA, 2005), a área de estudo apresenta uma superfície diversificada do ponto de vista geomorfológico e paisagístico, que despertou o interesse pela espacialização dos compartimentos do relevo através da análise de seus aspectos geomorfológicos. Os resultados advindos dessa proposta podem auxiliar no melhor entendimento da área e contribuir para a sua valorização enquanto Unidade de Conservação.

Neste contexto, o objetivo do presente trabalho foi realizar a compartimentação do relevo do Chapadão do Diamante (ChD) na Serra da Canastra (MG), por meio da aplicação da análise geomorfométrica com a utilização de um Modelo Digital do Terreno, tendo como base a metodologia de mapeamento proposta por Ross (1992). Portanto, buscou-se a apresentação de uma abordagem que conciliasse métodos tradicionais e modernos na avaliação e classificação do relevo (NAZAR, 2018).

\section{Área de Estudo}

O Chapadão do Diamante (ChD), toponímia designada para caracterizar a área de topo da Serra da Canastra em sua porção oriental, é uma superfície peculiar constituída predominantemente por rochas quartzíticas. Trata-se de um monumento geomorfológico de grande exuberância quando associado às escarpas abruptas que o circundam, cujo conjunto define a Serra da Canastra. Essa forma de relevo faz parte de um outro grande complexo estrutural que também engloba a Serra da Babilônia e os vales associados, o qual determina a delimitação da Unidade de Conservação do Parque Nacional da Serra da Canastra (PARNA Canastra). Está localizado no município de São Roque de Minas, cerca de $320 \mathrm{~km}$ de Belo Horizonte, capital do estado de Minas Gerais (Figura 1).

Conforme classificação de Ab'Sáber (2003), a Serra da Canastra faz parte da área de transição do Domínio das Áreas Mamelonares Tropical-atlânticas Florestadas para o Domínio Morfoclimático dos Chapadões Tropicais Interiores com Cerrados e Florestas-galeria, com predomínio de feições típicas de Cerrado. Sob a classificação de Ross (2006), a região está integrada ao compartimento de relevo dos Planaltos e Serras de Goiás-Minas, inserida no contexto da Faixa Brasília. Saadi (1991), em sua proposta de compartimentação morfoestrutural para a Porção Meridional do Cráton do São Francisco e a Bacia do Alto São Francisco, considera a Serra da Canastra situada no compartimento dos Planaltos Marginais Elevados.

Na perspectiva morfotectônica, de acordo com este último autor, a região compreende o Planalto da Serra da Canastra, que constitui um apêndice do Planalto do Alto Paranaíba. Estas estruturas, outrora, se juntavam através de um grande planalto na direção NNW, tendo sido soerguidas em pelo menos $400 \mathrm{~m}$ de altura (idade máxima do Plioceno). Foram, posteriormente, separadas por uma faixa de cisalhamento $\mathrm{N} 50 \mathrm{~W}$, que rebaixou a área delimitada localmente pelos rios Samburá e Mutuca (associado ao período Quaternário), e encontram-se fraturadas em várias direções tectônicas (períodos Terciário e/ou Quaternário). O topo aplainado da Serra da Canastra é correlacionado por Saadi (1991) à Superfície SulAmericana, considerando que após a sedimentação Cretácea, desenvolveu-se uma extensa superfície de erosão (Paleógena).

Segundo o mapa de compartimentos do relevo apresentado pelo MMA/IBAMA (2005), a Serra da Canastra compreende o Compartimento das Chapadas, 
que pode ser subdividido em Chapadão do Zagaia a oeste e Chapadão do Diamante a leste, constituídos por feições do tipo aplainadas, com vertentes suaves e cristas rochosas. Para Souza e Rodrigues (2014), a área situa-se no compartimento morfoestrutural da Faixa Canastra, compreendida pela Unidade Morfoescultural de Superficie Cimeira, correspondente ao topo da Serra da Canastra.

De acordo com Valeriano et al. (2004) a estruturação da região resulta da evolução do arcabouço geológico da Faixa Brasília Meridional (FBM), considerada como um ramo de orientação NW do Sistema Orogênico Neoproterozoico da Província Tocantins. A FBM resulta da interação entre os Crátons do São Francisco e Paranapanema (coberto pela Bacia do Paraná), e engloba a faixa de relevos serranos da Serra da Canastra. As litologias que caracterizam essa área são representadas pelo Grupo Canastra, que compreende a lasca tectônica inferior da Sinforma de Araxá, uma dobra regional cujo eixo cai de modo suave para WNW, com flancos de direção WNW e mergulhos para NNE e SSW; formando um conjunto de três lascas tectônicas separadas por falhas de empurrão, cada uma referente aos grupos Araxá, Ibiá e Canastra (VALERIANO et al., 2004; UHLEIN et al., 2012).

A área de estudo faz parte do conjunto de litologias do Grupo Canastra, subdividido em Unidades Formais e Canastra Indeterminado. Este último é formado por duas unidades litoestratigráficas: a inferior constituída por um pacote de filitos bandados intercalado por quartzitos (metarenito), e a superior, composta pelo pacote de quartzitos puros a micáceos com raras intercalações de muscovita filito; sendo responsável por sustentar a Serra da Canastra, onde está assentado o ChD (SIMÕES et al., 2015).

Além disso, o ChD destaca-se por abranger nascentes de duas grandes bacias, como as do Rio São Francisco (incluindo a nascente histórica) e do Rio Paraná, e constitui-se como uma larga cabeceira de drenagem de notório peso no cenário hidrológico regional. Conforme MMA/IBAMA (2005), a área faz parte de uma complexa zona de recarga regional, determinada pelas áreas de altitudes elevadas na região da Serra da Canastra, onde os aspectos litológicos exercem forte influência no comportamento dos fluxos da água, tanto em superfície, quanto em subsuperfície. Tais condições são observáveis em relação às características das coberturas superficiais do $\mathrm{ChD}$, que apresentam ao longo das vertentes uma variação da umidade, a qual, se intensifica na época das chuvas, chegando a formar pontos de exutório das águas meteóricas.

A área situa-se em região de clima Tropical típico, com duas estações bem definidas; sendo a úmida caracterizada pelo excedente hídrico no trimestre de dezembro a fevereiro; e a seca que ocorre mais acentuada entre junho e agosto, sendo estes também os meses mais frios. A pluviosidade varia entre os 1000 e $1500 \mathrm{~mm}$ e a temperatura média fica entre os $18^{\circ} \mathrm{C}$ no mês mais frio e os $22^{\circ} \mathrm{C}$ no mês mais quente (NOVAIS, 2011). Cabe ressaltar o papel do relevo enquanto condicionante orográfico, que diferencia as temperaturas e sensações térmicas no alto da Serra da Canastra, favorecendo e influenciando os aspectos vegetacionais do $\mathrm{ChD}$, haja vista as altitudes que variam de $1080 \mathrm{~m}$ a quase $1500 \mathrm{~m}$.

A esse respeito, ressalta-se que o $\mathrm{ChD}$ apresenta predominantemente as características do Domínio Morfoclimático do Cerrado, com variações fitofisionômicas desde campos limpos, sujos e rupestres, a formações de cerrado strictu sensu e matas de galeria (MMA/IBAMA, 2005). A vegetação herbácea e menos arbustiva predomina em grande parte da área, provavelmente em função das pequenas espessuras dos materiais superficiais e das temperaturas menos elevadas devido às altitudes ali presentes. Ao mesmo tempo, os campos rupestres são destaques sobre os extensos relevos com afloramentos quartzíticos, as formações de cerrado strictu sensu ocorrem associadas a padrões de coberturas superficiais mais profundas e desenvolvidas, e as matas de galerias em fundos de vales, próximas às formações anteriores.

\section{Materiais e Métodos}

Os procedimentos metodológicos para a realização do mapeamento geomorfológico do $\mathrm{ChD}$ englobam as etapas de: a) aquisição de informações, ou seja, montagem do banco de dados, a partir do levantamento bibliográfico, cartográfico, revisão metodológica e trabalhos de campo; e b) tratamento e análise dos dados, a partir da análise geomorfológica pautada nos aspectos geomorfométricos e geomorfográficos, aplicados em função da hierarquização do relevo proposta por Ross (1992). 


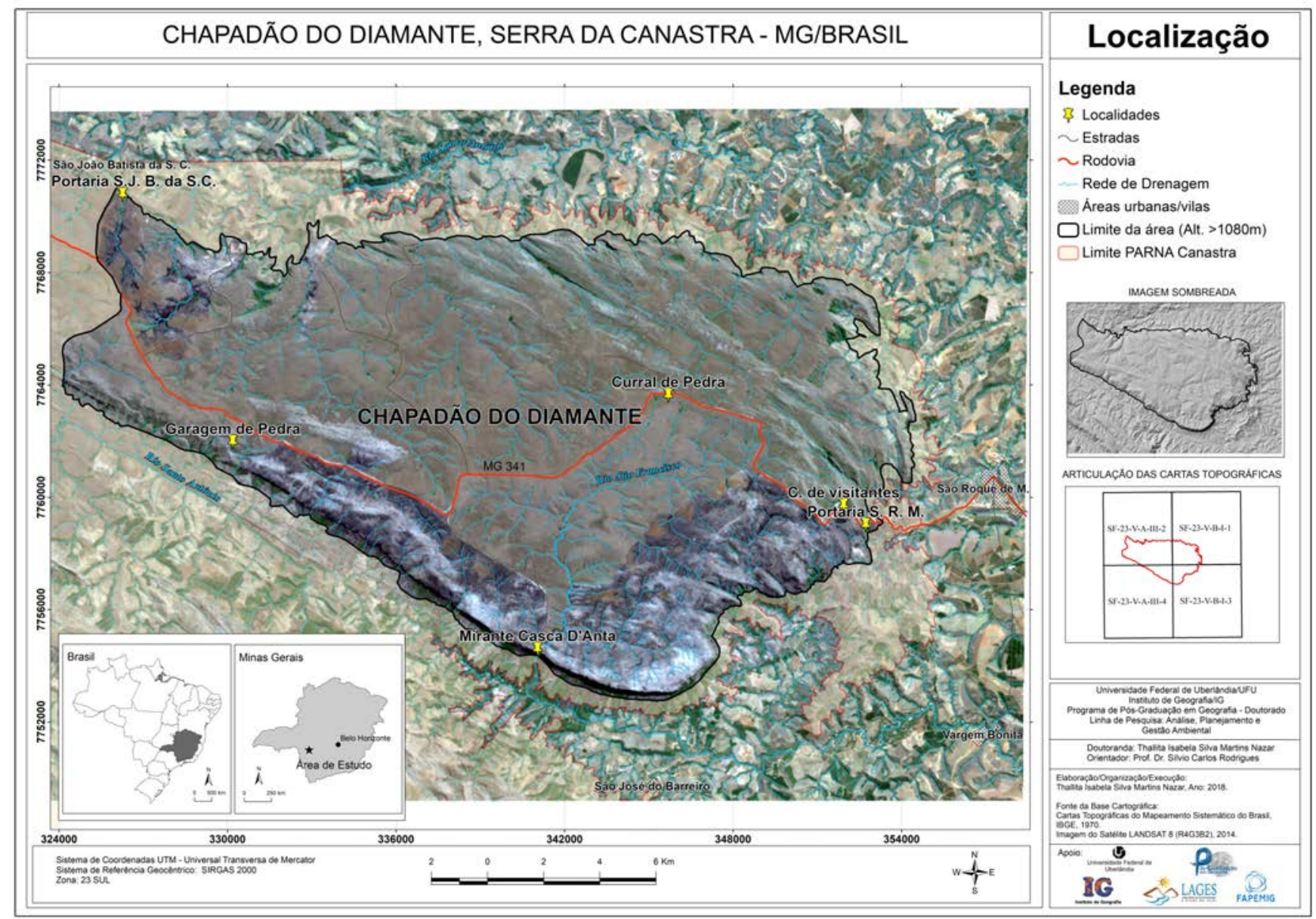

Figura 1 - Localização da área de estudo.

\section{Aquisição de Informações}

Nesta etapa de aquisição das informações, ou montagem do banco de dados, o levantamento bibliográfico e metodológico baseou-se na revisão de artigos de periódicos nacionais e internacionais, livros e capítulos de livros, teses e dissertações. No que se refere ao levantamento cartográfico, em relação aos mapas pré-existentes da área, apenas o Mapa Geológico foi encontrado, sendo: a) Mapa Geológico de Minas Gerais - escala 1:1.000.000 - CODEMIG (2014); e b) Mapa Geológico da Folha Vargem Bonita - escala 1:100.000 - CODEMIG (2015), que cobre parcialmente o ChD. Ainda são inexistentes mapeamentos em escalas de maior detalhe para a região e, devido ao mapa na escala 1:100.000 não cobrir a área completa, optou-se por juntar os mapas da CODEMIG $(b, c)$ para representar o ChD.

A plataforma de SIG utilizada corresponde ao conjunto de aplicativos da ESRI, denominado como ArcGIS versão 10.2 (licença Advanced). A base cartográfica foi constituída por meio das Cartas Topográficas do Mapeamento Sistemático do Brasil IBGE (1970) sendo que a área engloba quatro cartas na escala de 1:50.000, a saber: a) São Roque de Minas (SF-23-V-B-I-1); b) Serra da Canastra (SF-23-V-AIII-2); c) Vargem Bonita (SF-23-V-B-I-3); e d) Serra da Guarita (SF-23-V-A-III-4). Estas cartas serviram de base para a construção do Modelo Digital do Terreno Hidrologicamente Consistente (MDT-HC), com resolução espacial de 20 metros (em função da equidistância das curvas de nível), após etapas de vetorização e correções topológicas das variáveis curvas de nível, pontos cotados e rede de drenagem. O processo de interpolação dessas camadas permitiu a criação do MDT-HC, o qual, de acordo com Redivo et al.(2002); Valeriano (2003); Freitas et al.(2007) Lopes e Santos (2009); Gaboardi (2009); Arruda, Demattê e Chagas (2013); fornece, com maior propriedade, as características topográficas e morfométricas de determinada área. O método interpolador utilizado foi o Topo to Raster disponibilizado a partir do conjunto 
de ferramentas de Análise Espacial do ArcGIS, cujo algoritmo foi desenvolvido por Hutchinson (1989).

Por fim, para completar a montagem do banco de dados, os trabalhos de campo foram essenciais para a investigação empírica, reconhecimento da área, coleta de pontos de controle (GPS) e registro fotográfico, através da utilização de câmeras fotográficas comuns e imageamento por VANT - Veículo Aéreo Não Tripulado. Essa atividade constitui-se como de múltiplas etapas, pois é necessário, em um trabalho de mapeamento, a realização de saídas a campo prévias, durante e posteriores à execução do processamento dos dados da pesquisa.

\section{Tratamento e Análise dos Dados}

A base teórico-metodológica do mapeamento do relevo para esta pesquisa se apoia nos pressupostos de Ross (1992), que determinam a hierarquização das formas da superfície terrestre, a qual pode ser classificada em diferentes táxons $\left(1^{\circ}\right.$ ao $6^{\circ}$ táxon), conforme as suas dimensões e características. Em contrapartida, as técnicas de mapeamento digital, por meio de um SIG, são baseadas na utilização de um mapa geológico base e em parâmetros extraídos do MDT-HC, os quais devem ilustrar a hierarquização das formas de relevo a partir da aplicação de algoritmos semi-automatizados.

Divide-se as tarefas de mapeamento geomorfológico em duas partes principais: a análise morfoestrutural, regida pelas características litoestruturais, que são os aspectos controladores do relevo; e a análise morfoescultural, baseada nos aspectos morfográficos e morfométricos, este último cujos parâmetros são determinados a partir do MDT-HC com subsídio da geomorfometria. Tais parâmetros remetem aos conceitos de morfoestrutura e morfoescultura, abordados por Ross (1992; 2007) e que possuem origem nas concepções teórico-metodológicas construídas a partir da proposta de Walter Penck. Este último autor determinou, na década de 1920, a base para as pesquisas e análises geomorfológicas, na qual a sua natureza e princípio devem ser apoiados em três elementos-chave, a saber: os processos exógenos, os processos endógenos e os processos que resultam da interação entre os dois anteriores, chamados de feições atuais do relevo (ROSS, 2007). Além disso, os procedimentos metodológicos utilizados são decorrentes do aperfeiçoamento das aplicações realizadas por Martins e Rodrigues (2016), que realizaram o mapeamento geomorfológico da Folha Piumhi com base na taxonomia do relevo, utilizando rotinas semi-automatizadas sobre um MDE.

Dentro da perspectiva de hierarquia das formas de relevo, pode-se relacionar ao que Evans (2012) afirma sobre a aplicação da geomorfometria específica e geral na cartografia geomorfológica. $\mathrm{O}$ autor entende que são necessárias, tanto na geomorfometria quanto no mapeamento do relevo, abordagens gerais e específicas, isto é, de campo contínuo e de objeto, pois estas são complementares. Assim, é preciso utilizar ambos os conceitos para enriquecer mapas geomorfológicos múltiplos com numerosos mapas geomorfométricos, inter-relacionando-os em um ambiente SIG. Isso se deve ao fato de que a geomorfologia dedicou bastante esforço à classificação de diferentes padrões de superfícies terrestres (formas gerais de relevo) e ao reconhecimento de características específicas (formas elementares de relevo), bem como a correlações entre os atributos superficiais.

Neste sentido, a compartimentação geomorfológica apresentada neste trabalho chegou ao nível da geomorfometria geral, que de acordo com Evans (2012), engloba o estudo da land surface form (forma da superfície terrestre), que é contínua e cobre todo o globo, e pode ser estudada através dos padrões e associadas a escalas de semidetalhe ou pequenas. $\mathrm{Na}$ classificação hierárquica de Ross (1992), alcançou-se o terceiro nível hierárquico que caracteriza os padrões de formas semelhantes ou modelado do relevo.

A partir disso, utilizou-se os parâmetros da superfície terrestre (PSTs), fornecidos pelo MDT - HC, os quais, segundo Evans, Hengl e Gorsevski (2009), podem ser usados para produzir um mapa mais objetivo do que o delineado manualmente e ajudam a classificar a área de forma direta, utilizando um algoritmo semiautomatizado. Conforme exemplificam Pike, Evans e Hengl (2009), um dos principais conjuntos que representam os PSTs são os objetos e parâmetros morfométricos básicos, que descrevem a morfologia local da superfície terrestre, por exemplo, gradiente de inclinação, aspecto e curvatura.

Portanto, o presente trabalho apresenta as seguintes etapas de processamento da espacialização e análise geomorfológica do Chapadão do Diamante:

Trabalhos de campo pré e pós-análises: montagem 
do mapa mental, validação e verificação do mapeamento.

Análise morfoestrutural ( $1^{\circ}$ táxon): referente ao tipo crustal; à estrutura que sustenta o relevo; cujas informações são fornecidas pelo mapa geológico, condizente com os domínios de bacias sedimentares, crátons e faixas orogênicas ou móveis.

Análise morfoescultural ( $2^{\circ}$ e $3^{\circ}$ Táxons): unidades geneticamente homogêneas, oriundas de determinado tipo climático que atuou/atua sobre a estrutura, o que resulta em determinado tipo de modelado (Quadro 1).

Quadro 1: Síntese das análises morfoestruturais e morfoesculturais.

\begin{tabular}{|l|l|l|}
\hline Classificação & Descrição & Produtos Resultantes \\
\hline $1^{\text {o }}$ Táxon - Unidade Morfoestrutural & $\begin{array}{l}\text { - Unidade baseada no componente } \\
\text { litoestrutural. }\end{array}$ & $\begin{array}{l}\text { Classificação: Serra da } \\
\text { Canastra }\end{array}$ \\
\hline $2^{\circ}$ Táxon - Unidade morfoescultural & $\begin{array}{l}\text { - Litotipos específicos; gênese, } \\
\text { altimetria (MDT-HC). }\end{array}$ & $\begin{array}{l}\text { Classificação: Planalto } \\
\text { do Chapadão do } \\
\text { Diamante. }\end{array}$ \\
\hline $3^{\text {o }}$ Táxon - Unidades Morfológicas (Padrões) & $\begin{array}{l}\text { - Grau de dissecação do relevo } \\
\text { (ICR) (MDT-HC). } \\
\text { Densidade de drenagem (MDT-HC). } \\
\text { Topografia (MDT-HC). }\end{array}$ & $\begin{array}{l}\text { Mapa de Padrões de } \\
\text { Relevo. }\end{array}$ \\
\hline
\end{tabular}

No que se refere ao $3^{\circ}$ Táxon, correspondente à classificação em Unidades Morfológicas ou Padrões de Formas Semelhantes, a análise pautou-se na avaliação geomorfométrica de três parâmetros, tendo em vista o proposto por Ross (1992), que leva em consideração a gênese dos padrões de formas, a distância interfluvial e o grau de aprofundamento dos vales. Neste sentido, a presente compartimentação do relevo faz uma adaptação da metodologia e reflete os aspectos indicados no Quadro 2 e discutidos em seguida:

Quadro 2: Elementos de entrada para a compartimentação do relevo.

$$
\begin{gathered}
\text { DENSIDADE DE DRENAGEM } \\
\text { (distância interfluvial) } \\
X \\
\text { ÍNDICE DE CONCENTRAÇÃO DA } \\
\text { RUGOSIDADE } \\
\text { (aprofundamento dos vales) } \\
+ \\
\text { DENSIDADE TOPOGRÁFICA } \\
\text { (diferença altimétrica) }
\end{gathered}
$$

Densidade de Drenagem (DD) que representa a distância interfluvial de Ross (1994) de modo inversamente proporcional, sendo que quanto maior a densidade de drenagem, menor é a distância interfluvial, sendo calculada a partir da densidade de feições em torno de uma determinada vizinhança. A
DD é considerada, de acordo com Christofoletti (1980), uma das variáveis mais importantes para as análises morfométricas por representar o grau de dissecação topográfica, em paisagens elaboradas pela atuação fluvial; além de expressar a quantidade disponível de canais para o escoamento e o controle exercido pelas estruturas geológicas.

\section{Índice de Concentração da Rugosidade (ICR)} é o modelo apresentado por Sampaio e Augustin (2014), que reflete a distribuição espacial (densidade) da declividade do terreno, podendo representar os graus de aprofundamento dos vales em três dimensões, eliminando o efeito bidimensional da análise por perfis topográficos. Os graus de declividade estão diretamente relacionados aos aspectos de dissecação do relevo, em que as concentrações de classes maiores ou menores de declividades definem os ICRs de muito baixos a muito altos, de modo proporcional.

Densidade Topográfica (DT) baseia-se na análise das posições topográficas (TPI -Topographic Position Index) apresentada por Weiss (2001), a qual compara os valores de elevação de cada célula em um Modelo Digital de Elevação à altitude média de uma vizinhança específica em torno de determinada célula. Neste sentido, a DT determina a variação espacial da diferença altimétrica, cuja análise da superfície contínua reflete a existência de diferentes compartimentos de relevo a partir dos valores das cotas topográficas, além disso, a topografia pode indicar, a partir dos diferentes níveis altimétricos, variações de formas, substrato e 
materiais superficiais. Essa variável deve ser levada em consideração, pois permite uma maior aproximação da realidade do relevo de determinada área, sendo o fator delimitador entre padrões de formas, por exemplo, padrões em morros e/ou colinas.

O algoritmo responsável pela execução dos cálculos das densidades refere-se ao Estimador de Densidade por Kernel (KDE, Kernel Density do conjunto de ferramentas de Análise Espacial), um método estatístico de estimação não paramétrico de curvas de densidades, cujas observações são ponderadas pela distância em relação a um valor central, ou seja, a partir do núcleo; sendo considerado uma alternativa para análise geográfica do comportamento de padrões (BEATO; ASSUNÇÃO, 2008; MEDEIROS, 2016).

Após a aplicação do KDE foi necessário reclassificar os valores em uma escala numérica simples, de 1 a 5, por meio da ferramenta Raster Reclassify (ArcMAP), que devem representar os índices em (1) muito baixo, (2) baixo, (3) médio, (4) alto e (5) muito alto, respectivamente. Em seguida, procedeu-se à aplicação da ferramenta de Calculadora de Raster da seção de Álgebra de Mapas, também pertencente ao conjunto de ferramentas de Análise Espacial. Utilizou-se como arquivos de entrada a $\mathrm{DD}$, que reflete a distância interfluvial, e o ICR, que representa a rugosidade do terreno (análogo à definição de Ross), com a aplicação do cálculo por produto. $\mathrm{O}$ resultado foi um arquivo raster com classes que variam entre os múltiplos de 1 a 5 . Este arquivo, juntamente ao raster de DT, foi convertido para o formato vetorial (shapefile), o que permitiu a aplicação da ferramenta Union, de sobreposição (Overlay). Os arquivos vetoriais do produto DDxICR mais o DT foram sobrepostos, criando um novo arquivo DD_ICR_DT.

Nesta concepção, a topografia foi o elemento diferenciador e limitador das unidades de relevo mapeadas, uma vez que a altitude das feições interferiu em sua classificação, por exemplo, uma área com índice 1 , que consiste em muito baixa densidade de drenagem e ausência de declive, dependendo da sua posição no relevo, que é fornecida pelo arquivo DT, pode ser classificada como "topos planos" ou "planícies".

Neste momento, foi necessário tomar como base o mapa mental elaborado sobre a área de estudo, sendo essa uma etapa básica, subsidiada pelos trabalhos de campo prévios, o que permitiu o reconhecimento antecipado dos principais padrões de relevo presentes, aperfeiçoando a classificação com o auxílio do MDTHC. Portanto, criou-se uma chave para classificação do relevo no $\mathrm{ChD}$, com base nos valores numéricos $\mathrm{e}$ conhecimento de campo, conforme o Quadro 3.

Quadro 3: Classificação dos resultados do produto DDxICR.

\begin{tabular}{|c|c|c|c|c|}
\hline Índices (DDxICR) & Nomenclatura & DD & ICR & TOPO \\
\hline 1 & Topos planos & 1 & 1 & 4 \\
\hline $2,3,4$ & Colinas Suaves & $1,2,3$ & $1,2,3$ & 3 \\
\hline $6,8,9,12$ & $\begin{array}{c}\text { Colinas } \\
\text { onduladas }\end{array}$ & $2,3,4$ & $2,3,4$ & 3 \\
\hline $10,15,16$ & $\begin{array}{c}\text { Colinas } \\
\text { Fortemente } \\
\text { Onduladas }\end{array}$ & $2,4,5$ & $2,4,5$ & 3 \\
\hline 20,25 & Morros & 4,5 & 4,5 & 1,2 \\
\hline 20,25 & $\begin{array}{c}\text { Morros com } \\
\text { afloramentos } \\
\text { quartzíticos }\end{array}$ & 4,5 & 4,5 & 5 \\
\hline 5 & $\begin{array}{c}\text { Escarpas, Picos, } \\
\text { Fundos de vales }\end{array}$ & 1,5 & 1,5 & 3 \\
\hline
\end{tabular}

Entretanto, a chave de interpretação necessitou de alguns ajustes manuais, uma vez que os testes realizados de forma puramente automática não forneceram resultados definitivos e satisfatórios. Ainda houve a necessidade de classificação manual complementar dos elementos e padrões de relevo, tendo em vista que a análise geomorfológica pressupõe uma diversidade de abordagens, tanto empírica quanto quantitativa. Neste sentido, cabe ressaltar que o $\mathrm{ChD}$, cujos limites são delineados, em grande parte, por escarpas com aproximadamente $300 \mathrm{~m}$ de desnível, apresenta situação peculiar de relevo com certa raridade de ocorrência na natureza, o que contribui para uma dificuldade de classificação da ferramenta utilizada. Assim, como a classificação automática não inclui a situação real das escarpas, ocorreram algumas divergências que precisaram ser corrigidas manualmente. Esta situação é peculiar à área de estudo desta pesquisa, cabendo a cada pesquisador compreender e distinguir a realidade de sua própria área de interesse, na aplicação da metodologia.

A etapa manual foi feita com o auxílio da ferramenta de Calculadora de Campo, aplicável em arquivos vetoriais, dentro da tabela de atributos. A ferramenta possui a capacidade de classificar automaticamente todas as classes pré-determinadas 
por meio da aplicação de uma expressão lógica com VBScript (Visual basic Script, ArcGIS 10.2). Além disso, foram traçados diversos perfis topográficos no intuito de verificar as classes de relevo geradas, o que contribuiu para a melhor caracterização dos compartimentos, bem como os limites das escarpas e as cristas referentes ao lineamento do relevo em algumas áreas. Realizadas as etapas descritas, pode-se sintetizar a metodologia

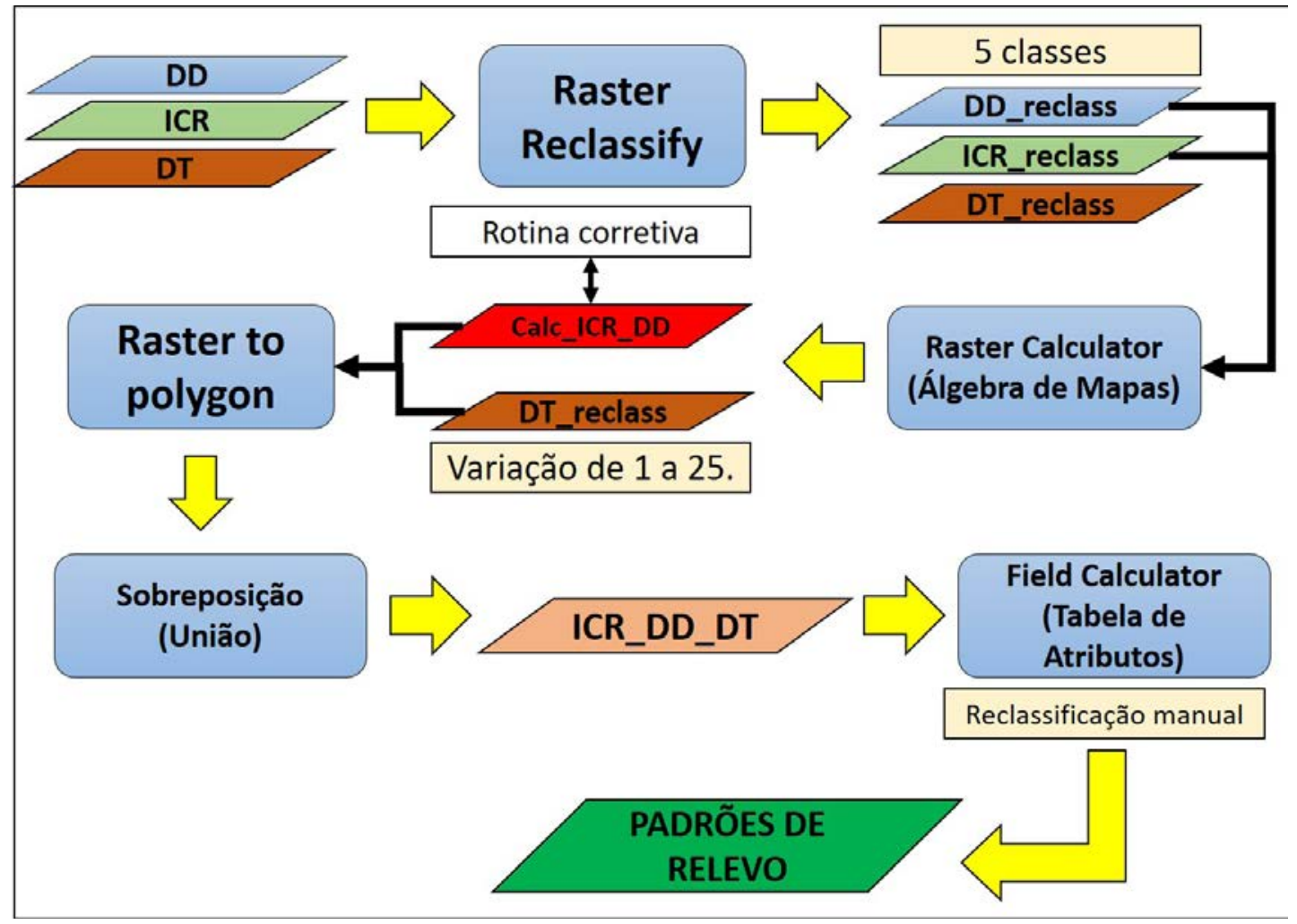

Figura 2 - Fluxograma da rotina metodológica para o mapeamento de classes de padrões de relevo ( $3^{\circ}$ Táxon).

conforme o fluxograma apresentado na Figura 2.

\section{Resultados}

A caracterização e o entendimento dos aspectos geomorfológicos do $\mathrm{ChD}$ basearam-se na compreensão da morfoestrutura e dos aspectos morfoesculturais que se destacam na configuração geral da área. Do ponto de vista estrutural, o ChD possui como base o arcabouço que sustenta a Serra da Canastra, derivada dos processos que formaram a Faixa Brasília Meridional e o Grupo Canastra (SAADI, 1991), ao longo de milhares de anos, constituindo assim o $1^{\circ}$ Táxon da classificação de Ross (1992), referente à Unidade Morfoestrutural. As rochas quartzíticas que sustentam o $\mathrm{ChD}$ são mais resistentes ao intemperismo, e mesmo em regiões tropicais, cuja atuação de um clima mais úmido incrementa os processos de dissecação do relevo, a intensidade desses processos acontece mais lentamente, o que preserva a grande estrutura da Serra da Canastra, com escarpas e relevo bem marcado. Porém, as marcas e registros topográficos em sua superfície revelam os resultados de um longo tempo de exposição aos agentes intempéricos e de degradação topográfica.

Neste sentido, ao tratar dos padrões de relevo do $\mathrm{ChD}$, observa-se estreita relação entre o substrato rochoso e a topografia, juntamente com os materiais superficiais que respondem a essa interação. A análise geomorfométrica, diretamente relacionada aos aspectos topográficos, forneceu subsídios para essa associação, quando se considerou o reconhecimento prévio em campo das feições físicas, atuando de forma quantitativa para minimizar os efeitos da abstração de um mapeamento geomorfológico tradicional. A metodologia aplicada resultou no mapa de padrões de relevo do $\mathrm{ChD}$, ao seguir a lógica de análise das densidades de drenagem, declividade e altimetria, associada aos aspectos observados em campo, com a execução de rotinas semi-automáticas e manuais. 


\section{Caracterização dos parâmetros morfométricos}

Em primeiro lugar, delimitou-se, dentro da fronteira da área de interesse, o limite altimétrico que constitui o $\mathrm{ChD}$ e as escarpas adjacentes, comportadas pelos quartzitos puros a micáceos do Grupo Canastra, correspondendo ao $2^{\circ}$ Táxon (Unidade Morfoescultural). Tendo em vista a ruptura de declive nitidamente observada, selecionou-se os seguintes intervalos: acima de $1080 \mathrm{~m}$, para definir o Planalto do Diamante; e abaixo de $1080 \mathrm{~m}$, para a área adjacente, conforme se nota na Figura 3 - B. Esta delimitação foi feita em função desta cota altimétrica ser o limite de altitude a partir do qual se iniciam as escarpas que circundam o Chapadão, perfazendo um área total de 333 $\mathrm{km}^{2}$. A variação da altitude para a área analisada, portanto, compreende o intervalo de $1080 \mathrm{~m}$ a $1496 \mathrm{~m}$, totalizando uma amplitude de $416 \mathrm{~m}$, sendo que, somente em área de escarpas, pode chegar a 350 metros de desnível a uma distância percorrida de $1 \mathrm{~km}$. As classes hipsométricas podem ser observadas na Figura 3 -A.

A nomenclatura do Planalto do Diamante, ora denominado Chapadão do Diamante, em conformidade com a cultura regional, por se pronunciar como uma vasta área horizontal, termo genericamente atribuído (IBAMA, 2005), é colocada devido ao fato de ser formado não apenas por áreas de topo planas, mas também por vertentes inclinadas e cristas alongadas, quando se observa localmente. No entanto, prevalece a nomenclatura já consagrada nacionalmente, sendo que aqui, apenas em termos científicos, se classifica como planalto, tendo em vista o significado dos termos no dicionário geológico-geomorfológico de Guerra e Guerra (2008). Para uma melhor visualização do relevo da área, o modelo tridimensional é apresentado em forma de blocodiagrama na Figura $3-\mathrm{C}$, a partir do qual verifica-se os diferentes níveis topográficos, com destaque para o Planalto (Chapadão do Diamante), as escarpas, a área rebaixada do entorno e a superficie residual entalhada referente à Serra da Babilônia.

A análise da densidade topográfica (DT), ilustrada pela Figura 4 - A, que determina a variação espacial da diferença altimétrica, indica que para o $\mathrm{ChD}$ a topografia se caracteriza com valores de média a alta DT. Esta diferenciação contribuiu para delimitar as unidades correspondentes à ocorrência de rochas quartzíticas puras e mais resistentes, formando relevos positivos na

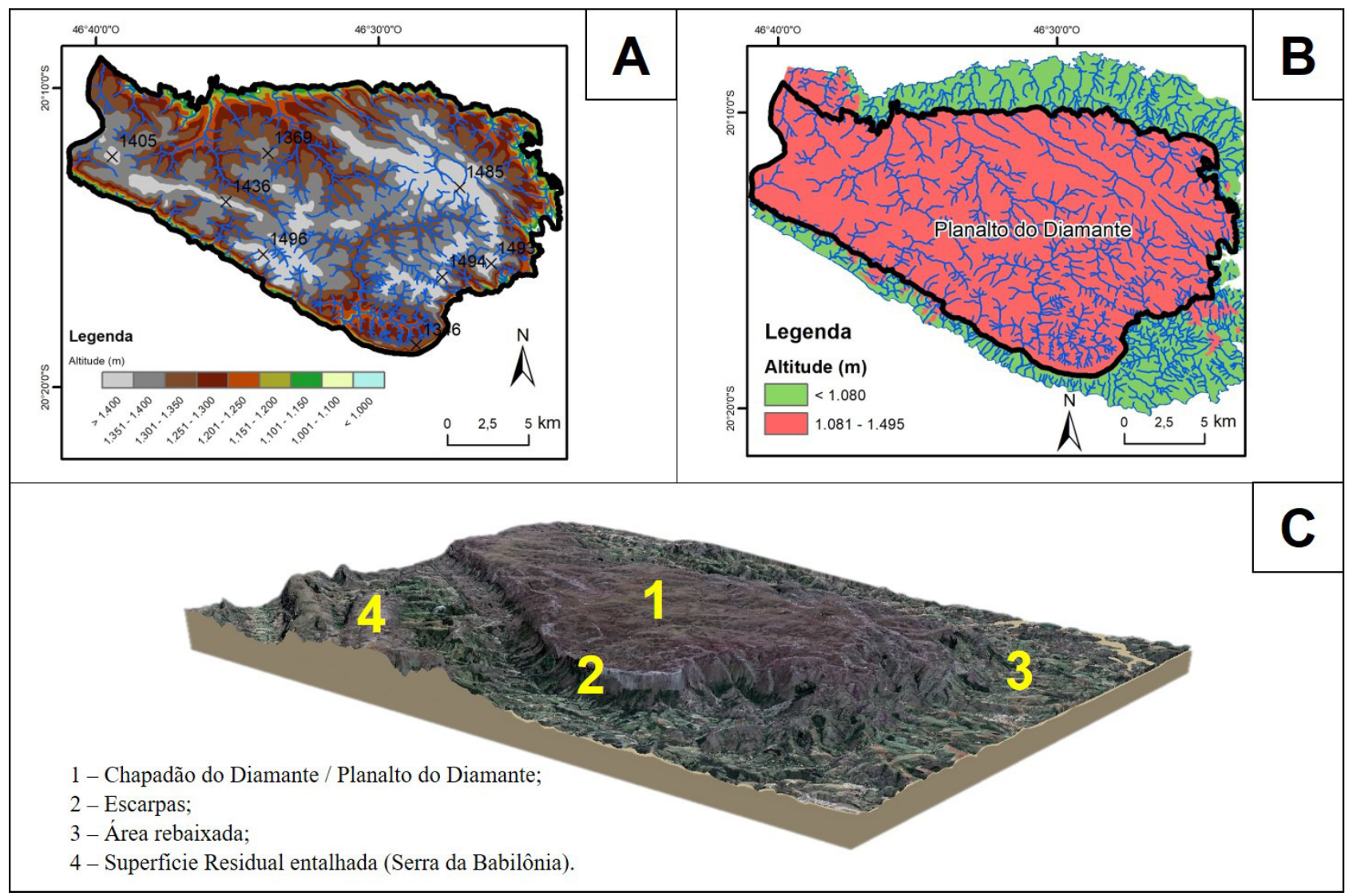

Figura 3 - Hipsometria (A); classificação do ChD (B) e bloco-diagrama (C). 
paisagem com inúmeros afloramentos rochosos.

A Figura 4 - B representa a espacialização das classes de declive identificadas, sendo possível observar que a superfície do $\mathrm{ChD}$ apresenta maior ocorrência de gradientes suaves a médios em sua porção central e nas áreas em direção às bordas, as características do relevo apresentam maior movimentação e, consequentemente, gradientes topográficos mais elevados. Nota-se a delimitação das áreas escarpadas, com forte ruptura de declive, em consonância com o observado no mapa hipsométrico a respeito do elevado desnível de altitude.

O parâmetro da densidade da declividade, abordada como o ICR de Sampaio e Augustin (2014), reflete os aspectos da dissecação do relevo, cujas classes delimitam padrões importantes para a análise geomorfológica, sendo que quanto maiores os índices encontrados, maiores são os declives e a rugosidade do terreno. Neste sentido, a Figura 4 - C mostra que sobre o $\mathrm{ChD}$, ocorrem as menores classes de ICR nas áreas centrais, refletindo a baixa rugosidade do terreno, enquanto as escarpas refletem o maior índice.

Em relação à densidade de drenagem (DD), este parâmetro também representa os graus de dissecação topográfica, contribuindo para a delimitação das classes de padrões de relevo em referência às distâncias interfluviais, sendo que quanto maiores, menores são os índices de DD, indicando a presença de superfícies planas e suaves. Esta variável é apresentada na Figura 4 - D, sendo possível observar uma variação dos menores índices na parte central e oeste do ChD, o que permite uma diferenciação entre as áreas de topo e as demais, onde aparecem as vertentes com graus de dissecação

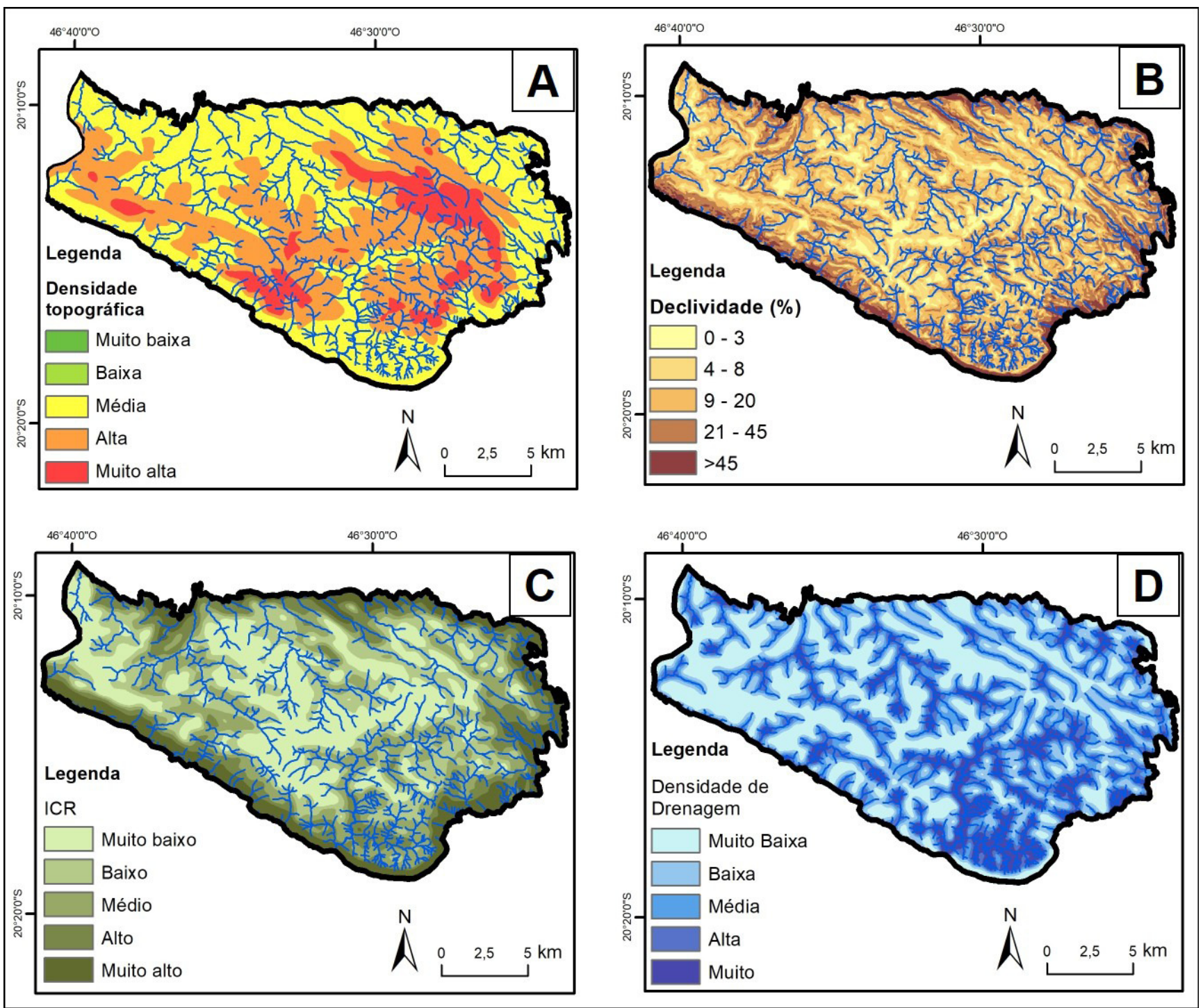

Figura 4 - Mapas resultantes das análises morfométricas. 
mais elevados.

\section{Mapa de Padrões de Relevo}

Os padrões de relevo ou unidades morfológicas, correspondentes ao $3^{\circ}$ Táxon da classificação de Ross (1992) que ocorrem no ChD, podem ser distribuídos, a partir das classes predominantes, em: Relevo suavemente dissecado associado a colinas suaves com $24,6 \%$ da área, seguida pelo Relevo dissecado associado a colinas onduladas com $20,4 \%$, e Relevo em cristas alongadas associado a afloramentos quartzíticos com $19,8 \%$. Enquanto que a classe de Relevo aplainado associado a interflúvios ocupa $12,6 \%$, a de Relevo fortemente dissecado associado a fundos de vales e de Relevo em escarpas estruturais associado a faces livres, englobam $11,4 \%$ do total cada uma.
A Figura 5 representa essa distribuição, sendo válido destacar que pouco mais da metade da área é composta por relevos moderadamente dissecados (suaves e ondulados a topos planos, $57,6 \%)$ e o restante $(42,6 \%)$ equivale a um relevo mais movimentado (fortemente dissecado a escarpado), indicando a predominância dos aspectos decorrentes da dissecação da superficie associada às rupturas de relevo resultantes da estruturação das rochas quartzíticas puras e micáceas da área. Outro ponto relevante é a grande quantidade de afloramentos observados, principalmente, nas áreas de cotas altimétricas mais elevadas, associadas às cristas quartzíticas, sendo possível, entretanto, encontrar afloramentos em todas as classes mapeadas, distribuídos de forma esparsa ou pontual. As Figuras 6 a 10 representam os diferentes compartimentos identificados, que podem ser verificados no mapa de Padrões de Relevo (Figura 11).

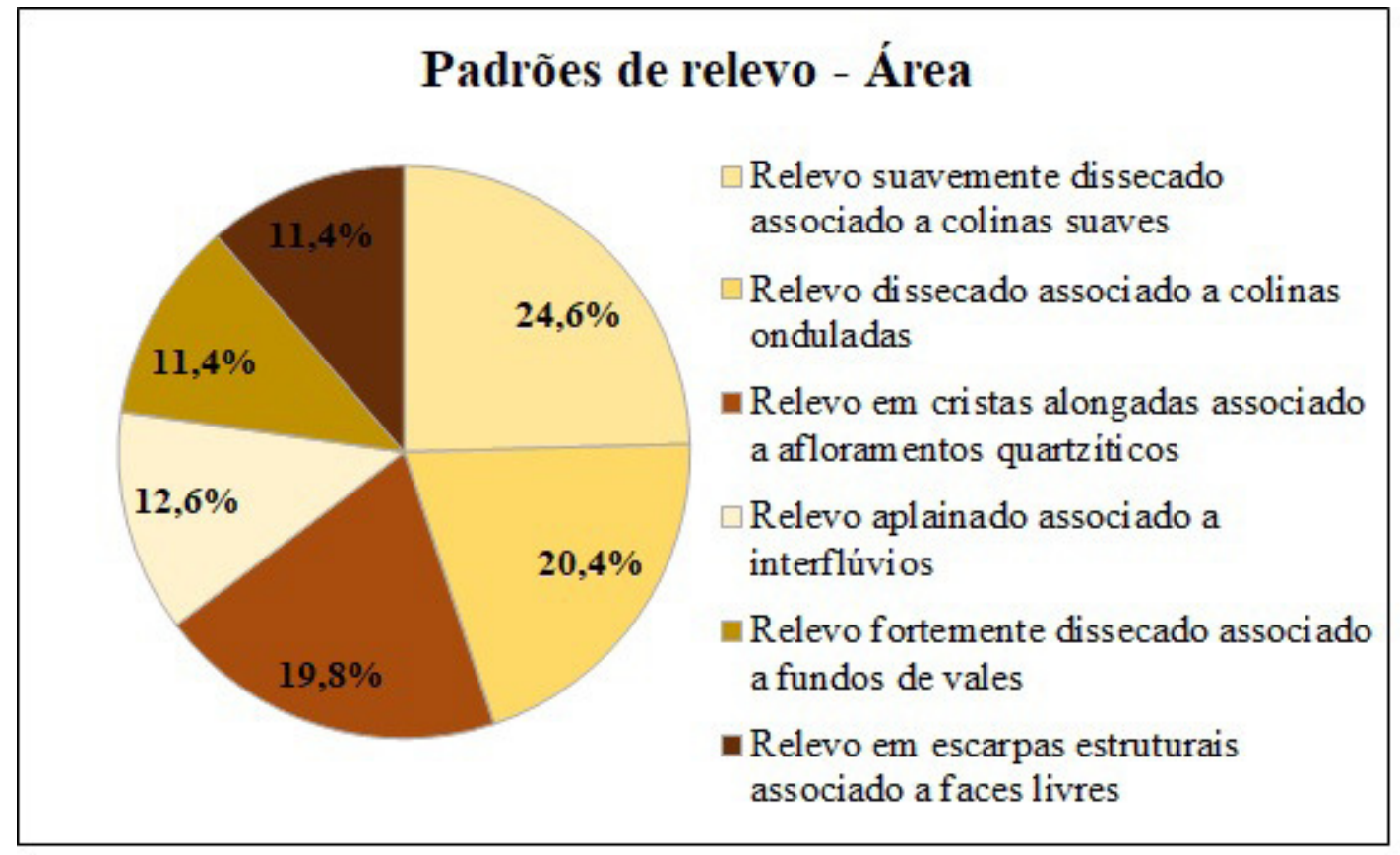

Figura 5 - Distribuição das áreas de padrões de relevo no Chapadão do Diamante.

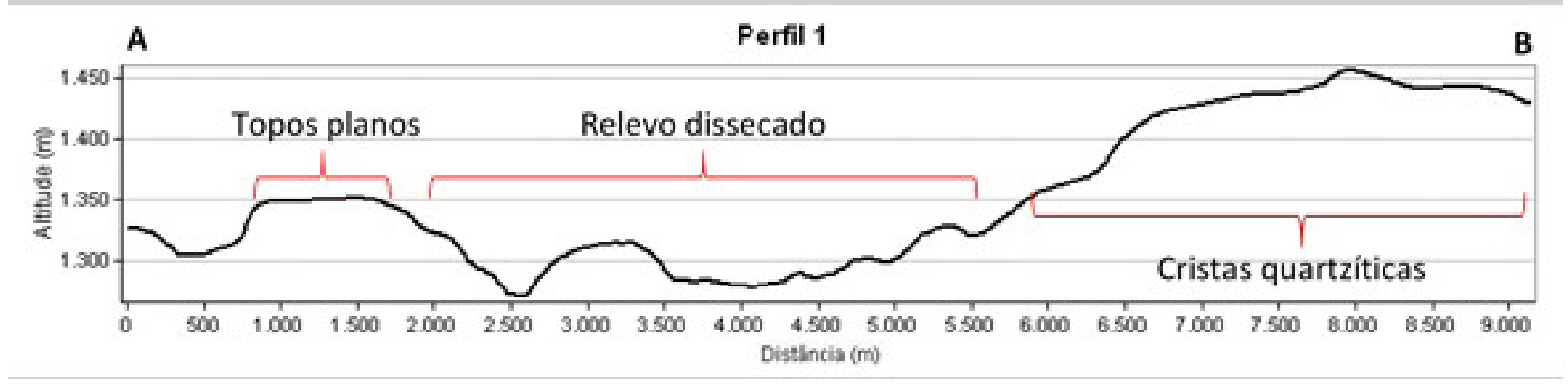

Figura 6 - Perfil topográfico - Secção A-B, área central do ChD. 


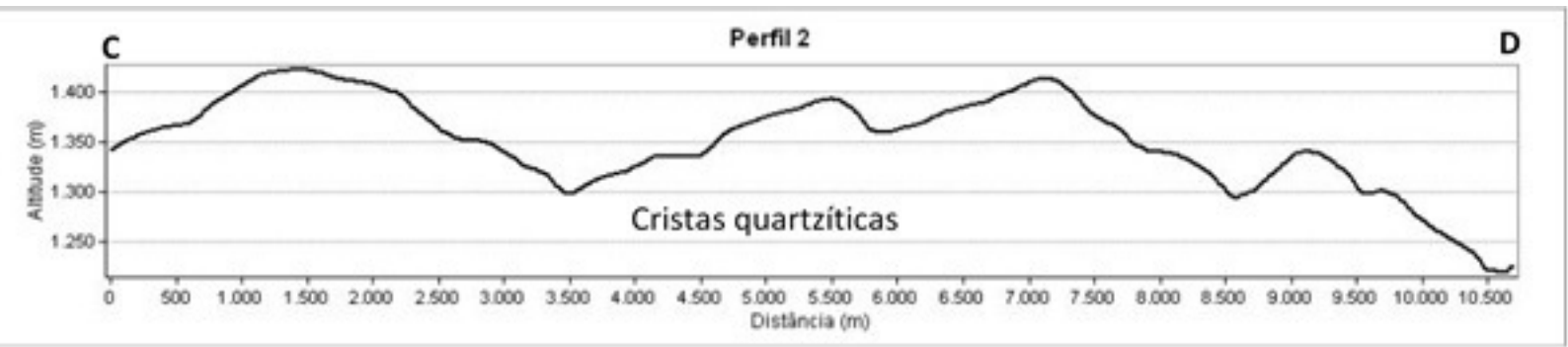

Figura 7 - Perfil topográfico - Secção C-D, área NE do ChD.

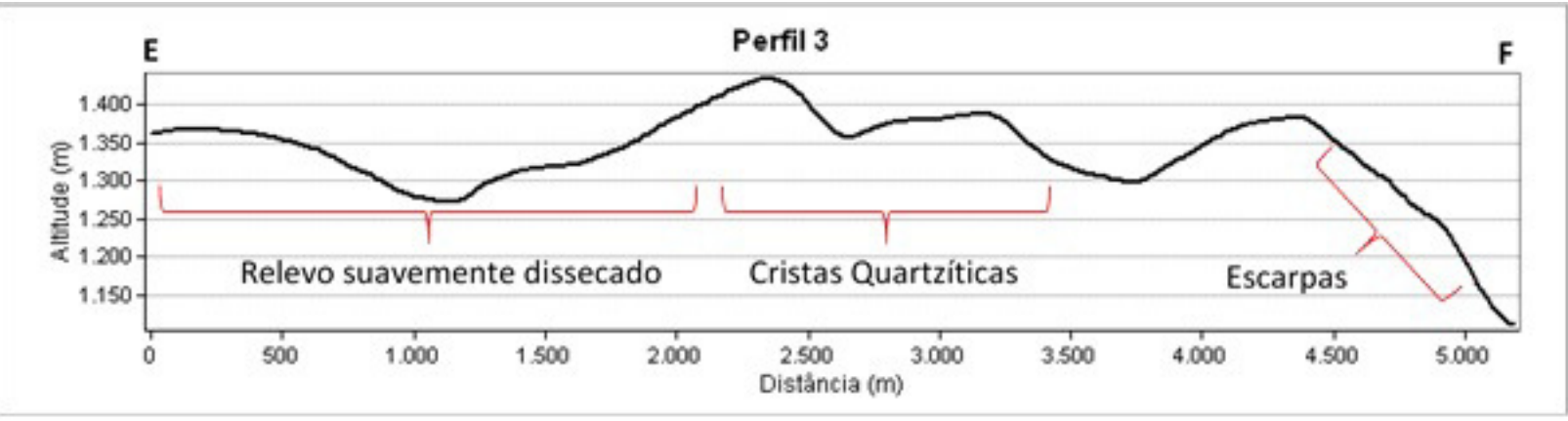

Figura 8 - Perfil topográfico - Secção E-F, área $S W$ do ChD.

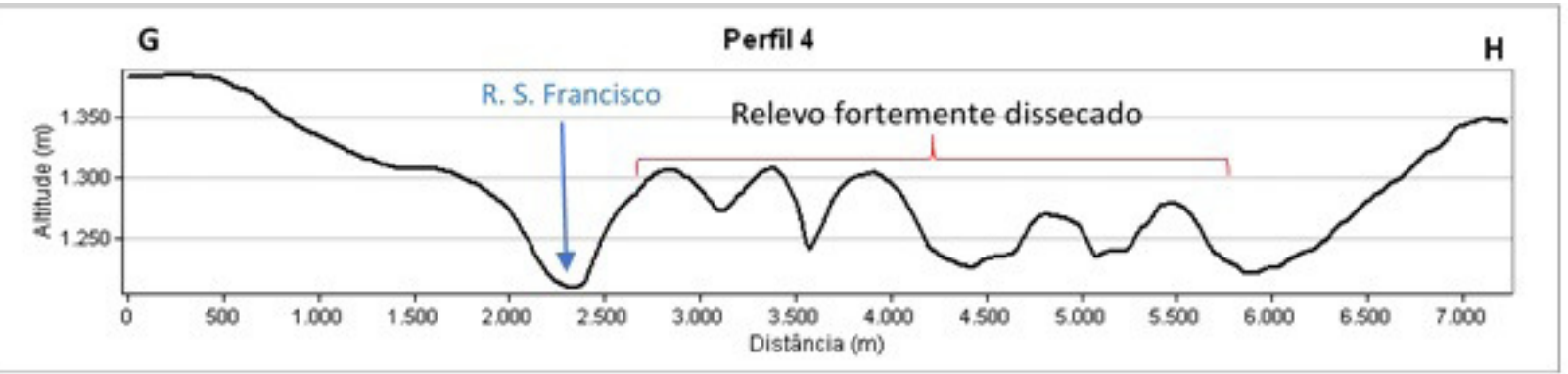

Figura 9 - Perfil topográfico - Secção G-H, área S do ChD.

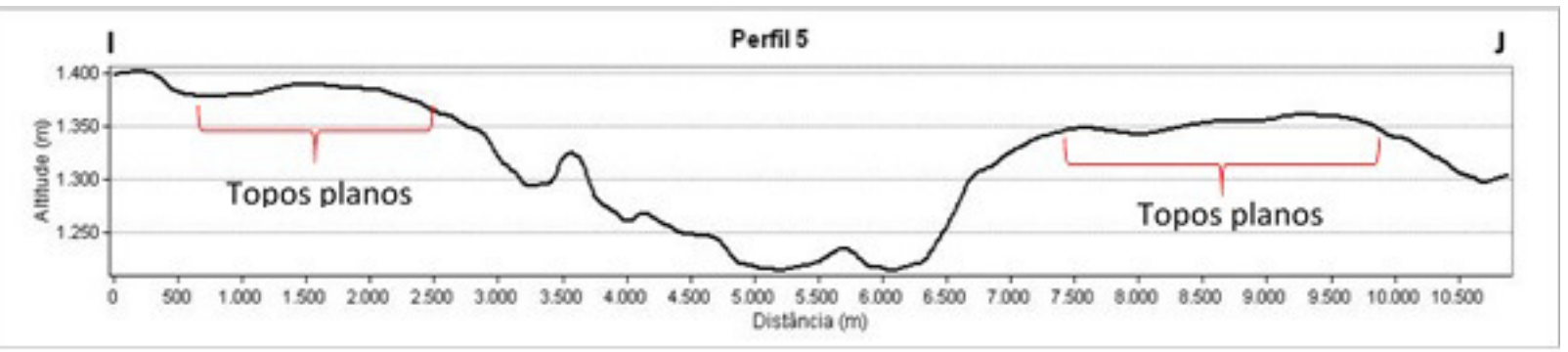

Figura 10 - Perfil topográfico - Secção I-J, área NW do ChD.

Diante do exposto, as classes de padrões de relevo representadas são descritas, tendo em vista as suas principais características, em função dos parâmetros morfométricos aplicados.

\section{Relevo suavemente dissecado associado a colinas suaves}

As formas suavemente dissecadas são predominantes no $\mathrm{ChD}$, caracterizando extensas áreas em colinas suaves, cuja distribuição ocorre nas áreas adjacentes dos topos aplainados, mormente na região central e NW do Chapadão. Tais formas geomorfológicas configuram uma transição de relevo suave em direção aos fundos dos vales, com acréscimo gradativo dos gradientes topográficos e baixa densidade de drenagem. Predominam vertentes convexo-retilíneas a retilíneas, bem como os materiais superficiais englobam os 
Nazar T. I. S. M. \& Rodrigues S. C.

cascalho-arenosos com ou sem concreções ferruginosas a materiais de bioturbação, representados por amplos campos de murunduns. Este tipo de padrão de formas pode ser observada nas imagens a seguir (Figura 12).

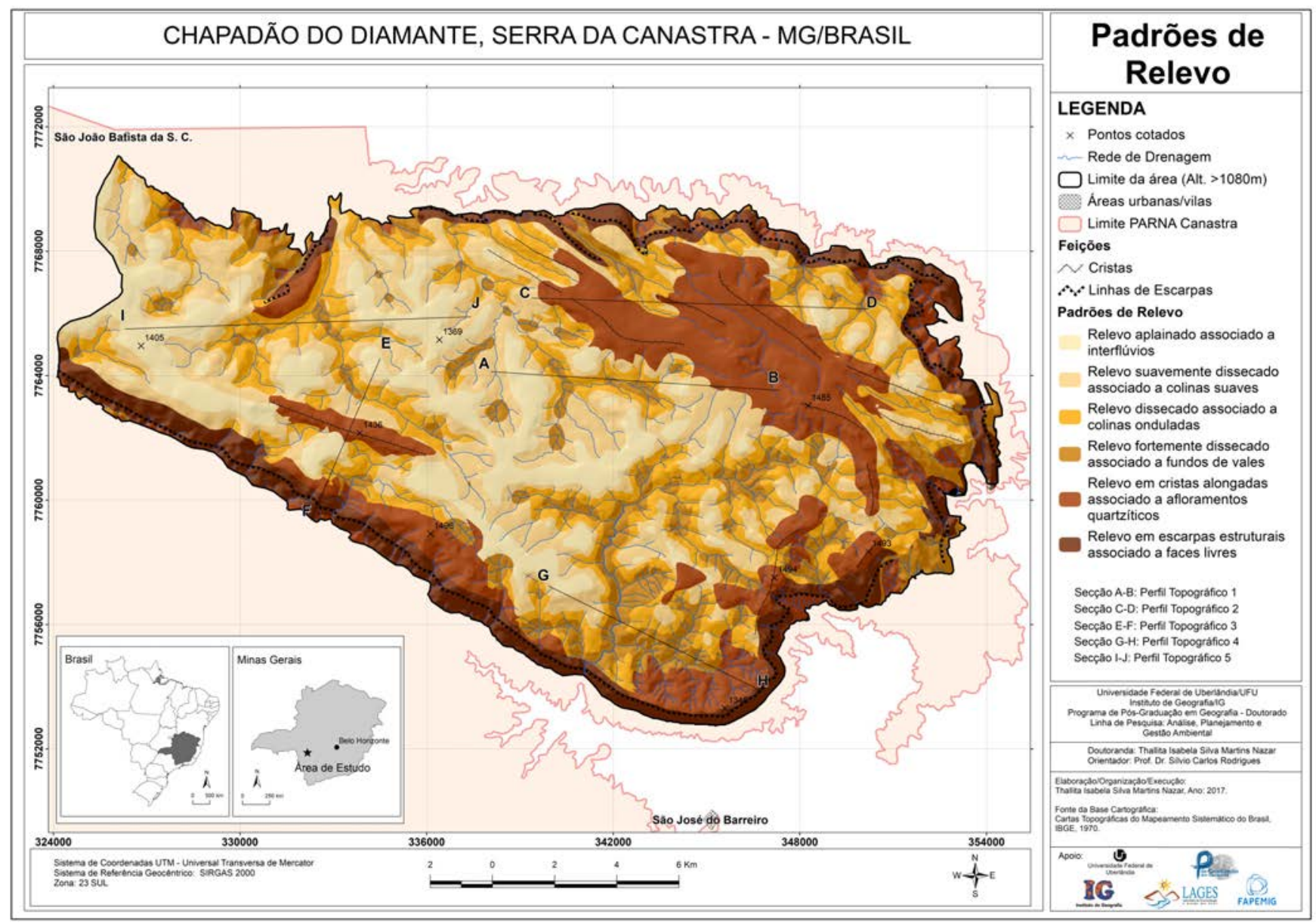

Figura 11 - Representação dos Padrões de Relevo do ChD e entorno.

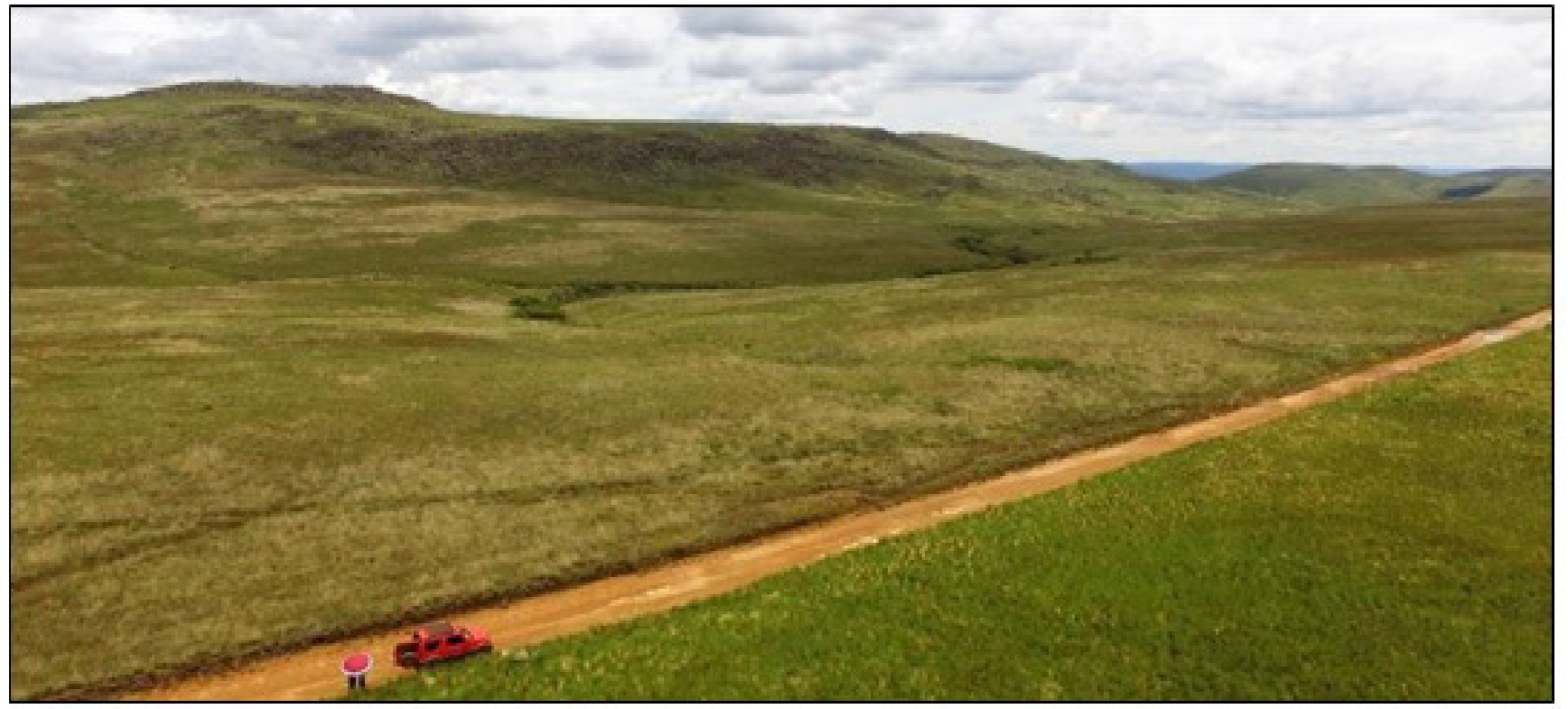

Figura 12 - Padrão de Relevo dissecado associado a colinas suaves, circundado por crista quartzítica. Imageamento por VANT. Autoria: NAZAR, jan. 2017. Coord. do ponto de visada: 20¹5’4,6754; 46³3'39,5213. Alt.: $1400 \mathrm{~m}$. 


\section{Relevo dissecado associado a colinas onduladas}

O padrão de relevo dissecado associado a colinas onduladas é caracterizado por menores distâncias interfluviais e consequente aumento dos graus de declividade, ocorrendo em locais com médias densidades de drenagem. Pode ser considerado como o conjunto de áreas adjacentes às colinas suaves e até mesmo aos morros quartzíticos, conforme se observa na Figura 13. Neste padrão, as vertentes ocorrem com segmentos convexos a convexo-retilíneos e, também, côncavos a côncavoretilíneos. No que se refere aos materiais superficiais, estes são diversos, podendo variar de cascalho-arenosos com ou sem caos de blocos e ocorrências de afloramentos rochosos esparsos, a material turfoso em áreas de fundos de vale. Como a segunda categoria mais recorrente no $\mathrm{ChD}$, esse padrão reflete a predominância dos processos de erosão ao longo das vertentes, ao mesmo tempo em que há formação de depósitos orgânicos na extensão das margens fluviais.

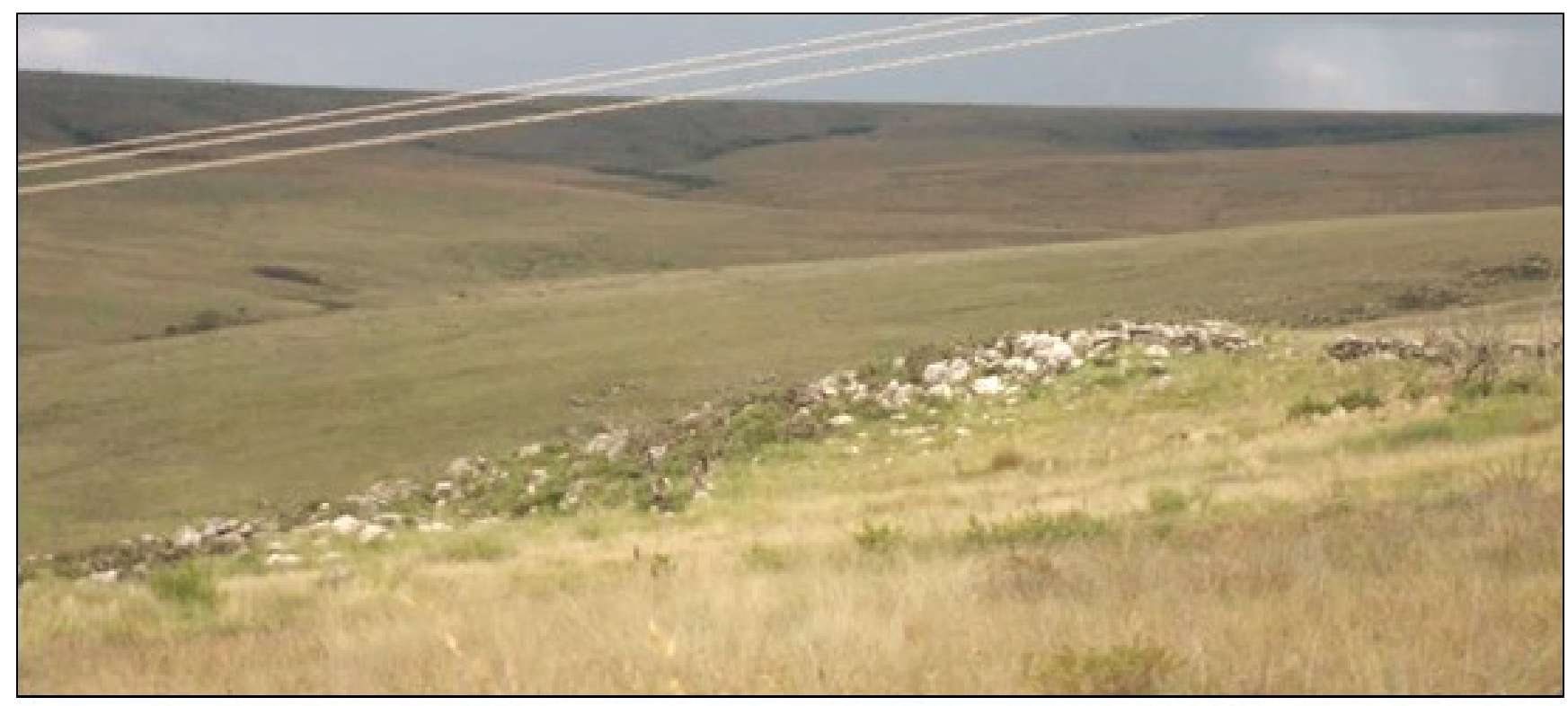

Figura 13 - Padrão de Relevo dissecado associado a colinas onduladas com algumas ocorrências de afloramentos rochosos. Autoria: NAZAR, fev. 2015.

\section{Relevo em cristas alongadas associado a afloramentos quartzíticos}

A classe de relevo em cristas alongadas associada a afloramentos quartzíticos refere-se às áreas do $\mathrm{ChD}$ que se destacam pelas maiores cotas altimétricas e, principalmente, pelas feições rochosas peculiares de características estruturais marcantes, como lineamentos e grandes massas rochosas aflorantes, sendo estas as características principais para delinear este padrão de relevo na área. As vertentes não obedecem a um padrão de curvatura bem definido, variando de côncavas a convexas, com trechos retilíneos. Os materiais superficiais, em tais áreas, são majoritariamente incipientes e cascalhoarenosos com caos de blocos, com predomínio de longos trechos de rocha quartzítica nua. Em tais áreas a tendência da declividade varia de baixa nos topos das cristas, a alta nas vertentes mais íngremes; com baixa densidade de drenagem (Figura 14).

\section{Relevo aplainado associado a interflúvios}

As formas de relevo caracterizadas como aplainadas associadas a interflúvios, ocorrem, predominantemente, na parte central do $\mathrm{ChD}$, direcionando-se em SE-NW. Nas áreas mais próximas ao vale do rio São Francisco, esses topos apresentam materiais superficiais incipientes, às vezes formados por cascalhos e concreções ferruginosas, com colorações variando do cinza ao amarelo e vermelho; a vegetação se mantém rasteira, com raros arbustos. À medida em que se afastam no sentido do rio Santo Antônio, a NW, percebe-se uma mudança significativa no padrão de materiais que recobrem os topos, quando estes se tornam mais profundos e de coloração avermelhada intensa, a cobertura vegetal também se modifica, aparecendo em alguns setores formações do tipo cerrado. Observa-se um rebaixamento do relevo no sentido SE-NW. Além disso, os topos planos podem ocorrer ocasionalmente em outras áreas espalhadas pelo $\mathrm{ChD}$. As 
imagens seguintes ilustram a paisagem dominada pelos padrões em topos planos (Figura 15).

\section{Relevo fortemente dissecado associado a fundos de vales}

A área de ocorrência dos padrões fortemente dissecados, associados a fundos de vales, destaca-se no vale do rio São Francisco, especialmente a montante da queda da cachoeira Casca D'Anta, sendo a área mais representativa dessas feições no $\mathrm{ChD}$. Estão associadas à ocorrência de alta densidade de drenagem, declives bastante acentuados e vales encaixados, sobrepostos por materiais inconsolidados de pequena profundidade e vegetação rasteira, com eventuais afloramentos de quartzitos; conforme se verifica na Figura 16.

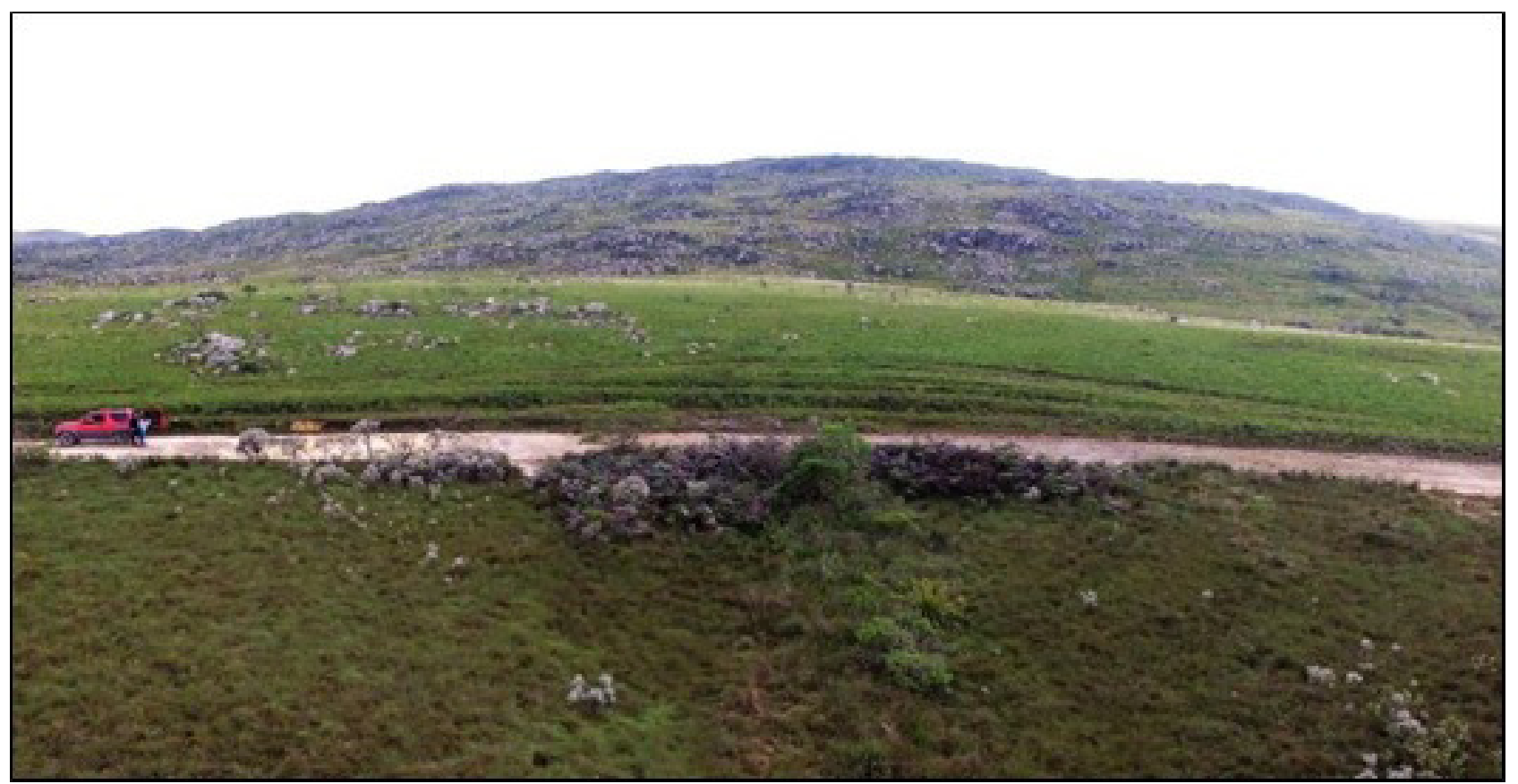

Figura 14 - Padrão de Relevo em cristas alongadas associado a afloramentos quartzíticos, imageamento por VANT. Autoria: NAZAR, jan. 2017. Coord. do ponto de visada: 20¹4’56,2373; 46²6’17,290. Alt.: $1400 \mathrm{~m}$.

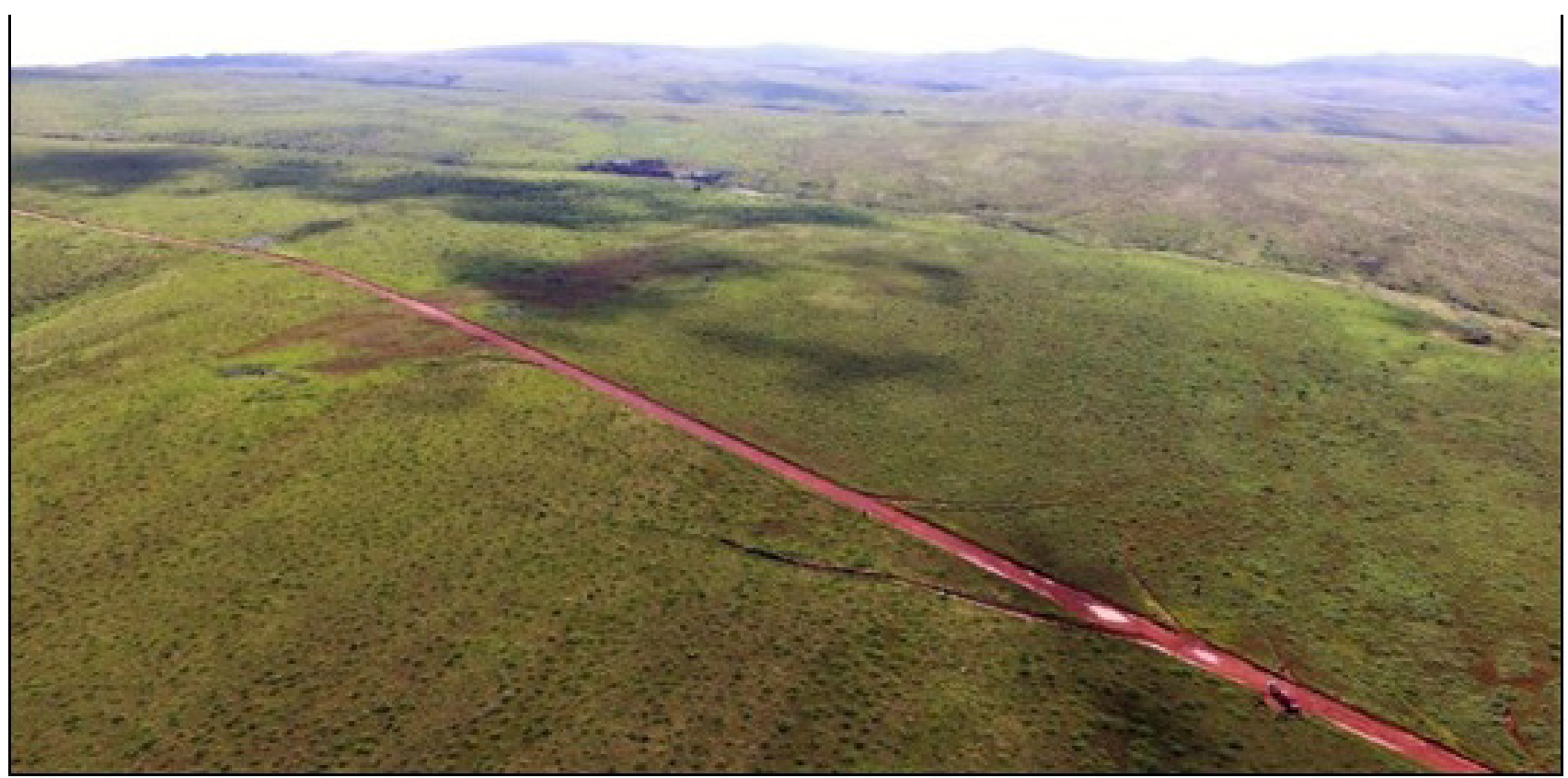

Figura 15 - Padrão de Relevo aplainado associado a interflúvios, imageamento por VANT. Autoria: NAZAR, jan. 2017. Coord. do ponto de visada: 20¹3'42,712; 46²9’33, 578. Alt.: $1481 \mathrm{~m}$. 


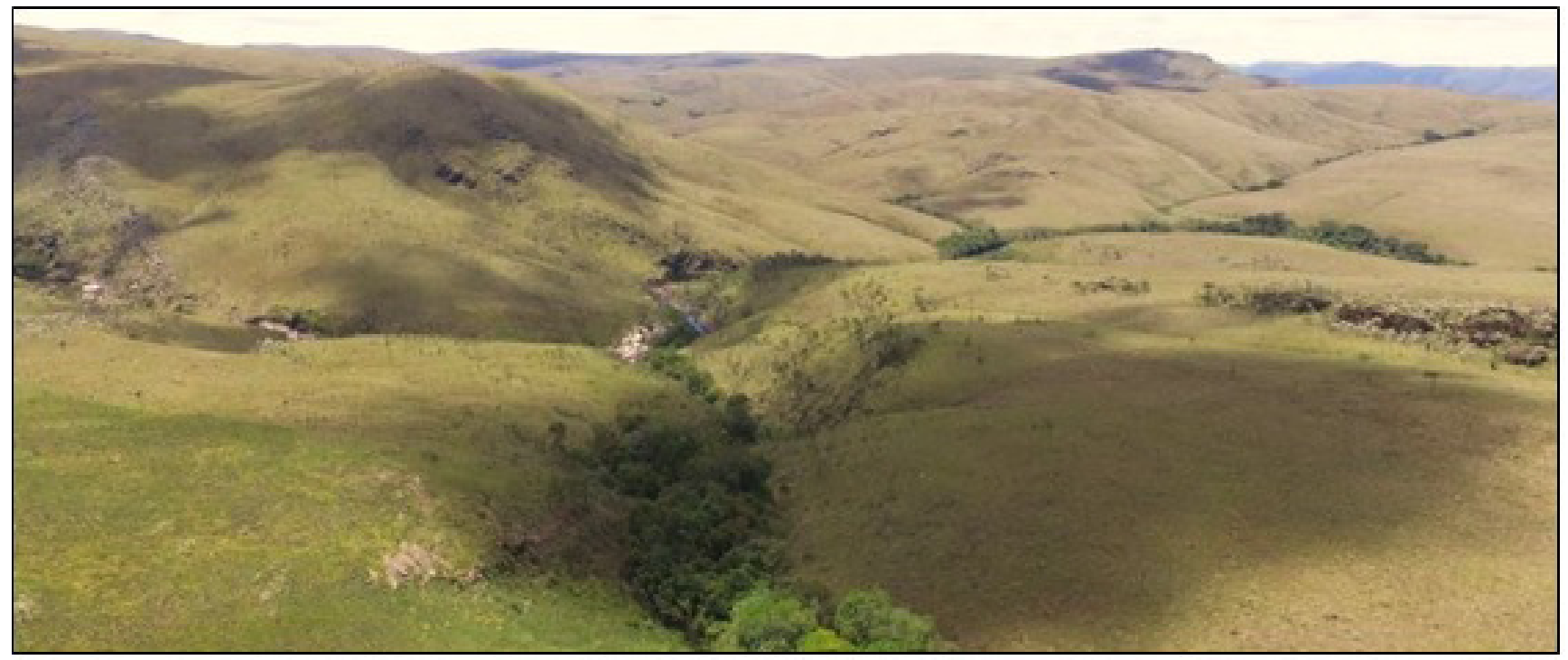

Figura 16 - Padrão de Relevo fortemente dissecado associado a fundos de vales, imageamento por VANT. Autoria: NAZAR, jan. 2017. Coord. do ponto de visada: 20¹7’11,694; 46³1'4,086. Alt.: $1300 \mathrm{~m}$.

\section{Relevo em escarpas estruturais associado a faces livres}

O padrão de relevo em escarpas corresponde às feições que delimitam o $\mathrm{ChD}$ da área do entorno. Apresentam declives, em média, superiores a $45^{\circ}$, podendo chegar a alcançar a marca de $58^{\circ}$ de inclinação. São formas de relevo abruptas, caracterizadas por súbitas rupturas de declive, formando paredões rochosos exuberantes. Em toda a extensão das escarpas é possível verificar a ocorrência de quedas d'água de dimensões variadas, o que contribui para o cenário de beleza cênica da região. É possível observar, também, os depósitos de talude no sopé dessas áreas, com destaque para blocos rochosos de tamanhos variados depositados na base da cachoeira Casca D'Anta seguindo o trecho do talvegue do rio São Francisco (Figura 17).

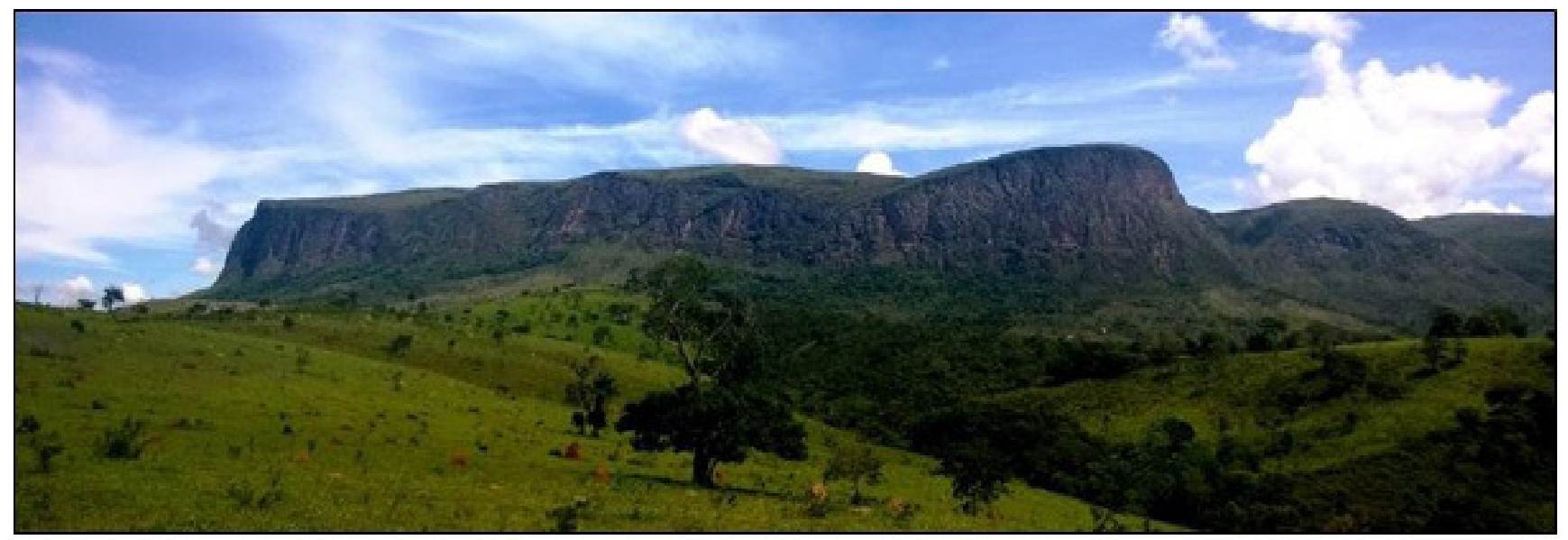

Figura 17 - Padrão de Relevo em escarpas estruturais, mirante setor S. Autoria: NAZAR, fev. 2015.

\section{Considerações Finais}

Com a evolução das geotecnologias, o mapeamento geomorfológico adquiriu maior precisão e praticidade, ao mesmo tempo em que enfrenta diversos desafios na tentativa de ultrapassar o limiar da semi-automatização de tarefas cartográficas para análise e espacialização do relevo. Entretanto, observa-se que as geotecnologias e os avanços das ferramentas de análise espacial do terreno colaboram para a caracterização geomorfológica de determinada área, com base em parâmetros geomorfométricos, mesmo em aplicações semi-automatizadas. 
Não obstante, é necessário atentar para o fato de que as análises em geomorfologia não devem se pautar puramente no estudo quantitativo do relevo, pois as variáveis que compreendem esse fenômeno tridimensional da natureza, requerem habilidades além das determinadas pelos números matemáticos. Assim, salienta-se a importância do conhecimento teórico e de campo prévio para aplicação das ferramentas de análise espacial e tridimensional em ambiente SIG.

Além disso, considera-se que o Mapa de Unidades de Relevo apresentado consegue preencher a lacuna de conhecimento a respeito da distribuição e diversidade das formas de relevo no Chapadão do Diamante, na escala proposta de 1:50.000. A associação entre os aspectos de densidade de declividade, constituindo a rugosidade do terreno, densidade de drenagem, que indica o grau de dissecação, bem como a densidade topográfica, que diferencia os níveis topográficos, contribuiu para a sistematização dos padrões de relevo no $\mathrm{ChD}$.

Portanto, foi possível estabelecer que os tipos de formas existentes são resultado, de um lado, da conformação litoestrutural, distribuída entre: a) quartzitos puros que estruturam cristas alongadas com declives mais acentuados, destacando-se positivamente na paisagem ao longo dos eixos nas bordas $\mathrm{N}$ e $\mathrm{S}$ da área, caracterizando geocoberturas cascalhoarenosas, com algumas ocorrências de caos de blocos $\mathrm{e}$, geralmente, de espessuras incipientes; b) quartzitos micáceos intercalados a filitos, que sustentam, em um eixo estrutural central, relevos aplainados e dissecados em diferentes graus, formando colinas suaves a onduladas, que sustentam geocoberturas cascalhoareno-ferruginosas, areno-argilo-ferruginosas ou cascalho arenosas indiferenciadas.

Por outro lado, os mesmos relevos aplainados podem ser suportados e preservados pela presença de camadas concrecionárias ferruginosas, como sendo resultantes da longa exposição aos processos intempéricos decorrentes do clima tropical, com suas oscilações sazonais, que interferem pelo balanço hídrico, a nível da variação do lençol freático, entre outros aspectos, bem como, a predominância de padrões dissecados em diferentes graus indica a atuação desses fatores climáticos sobre a estrutura litológica.

Em suma, espera-se com essa contribuição, o incremento das pesquisas geomorfológicas na área, seja no que se refere ao estudo dos processos e dinâmica, bem como, à origem e evolução da paisagem geomorfológica em questão.

\section{Agradecimentos}

Os autores agradecem pela bolsa de Doutorado da primeira autora fomentada pela Fundação de Amparo à Pesquisa do Estado de Minas Gerais - FAPEMIG (PAPG - GEOGRAFIA, 2014-2018), bem como, pelo projeto CRA APQ-00231-16 (FAPEMIG), que apoia a realização da pesquisa.

\section{Referências Bibliográficas}

ARRUdA, C.P.; DEMATTÊ, J.A.M.; CHAGAS, C.S. Mapeamento digital de solos por redes neurais artificiais com base na relação solo-paisagem. Rev. Bras. Ciênc. Solo, v. 37, n..2, p. 327-338, Viçosa Mar./Apr. 2013. https://doi.org/10.1590/ S0100-06832013000200004

AUGUSTIN, C.H.R.R.; FONSECA, B.M.; ROCHA, L.C. Mapeamento geomorfológico da Serra do Espinhaço Meridional: primeira aproximação. Geonomos, v. 19, n. 2, p. 50-69, 2011.

BEATO, C.; ASSUNÇÃO, R. Sistemas de Informação Georreferenciados em Segurança. In: BEATO, C. (Org.). Compreendendo e avaliando: projetos de segurança pública. Belo Horizonte: Editora UFMG, 2008. p. 11-62.

BISHOP, T.F.A. MINASNY, B. Digital soil-terrain modeling: the predictive potential and uncertainty. In: GRUNWALD, S. (Ed). Environmental Soil-Landscape Modeling, CRCPress. Boca Raton, Fla, USA, 2006. p.185-213. https://doi.org/10.1016/ S0016-7061(01)00074-X

CARNEIRO, C.D.R.; SOUZA, J. J. Mapeamento geomorfológico em escala de semidetalhe da região de Jundiaí-Atibaia. Revista Brasileira de Geomorfologia, São Paulo, v. 4, n. 2, p. 17-30, 2003. https://doi.org/10.20502/rbg.v4i2.21

CHRISTOFOLETTI, A. Geomorfologia. São Paulo: Edgard Blücher, 1980. 2 ed. $11^{\circ}$ reimpressão, 2008.

DINIZ, M. T. M.; OLIVEIRA, G.P.; MAIA, R.P. ; FERREIRA, B. Mapeamento Geomorfológico do Estado do Rio Grande do Norte. Revista Brasileira de Geomorfologia, São Paulo, v.18, n.4, (Out-Dez) p.689-701, 2017. https://doi.org/10.20502/rbg. v18i4.1255

EVANS, I.S. Geomorphometry and landform mapping: What is a landform? Geomorphology, 137, p. 94-106, 2012. https:// 
doi.org/10.1016/j.geomorph.2010.09.029

EVANS, I. S.; HENGL, T.; GORSEVSKI, P. Applications in geomorphology. In: HENGL, T.; REUTER, H. I. (Org.). Geomorphometry: concepts, software, applications. Developments in Soil Science, vol. 33. Amsterdam: Elsevier, 2009. p. 497-525. https://doi.org/10.1016/S0166-2481(08)00022-6

FONSECA, A.F. ZÊZERE, J.L.; NEVES, M. Contribuição para o conhecimento da geomorfologia da Cadeia da Arrábida (Portugal): Cartografia Geomorfológica e Geomorfometria. Revista Brasileira de Geomorfologia, São Paulo, v.16, n.1, (Jan-Mar) p.137-163, 2015. http://dx.doi.org/10.20502/rbg. v16i1.533

FREITAS, L.F.; CARVALHO JÚNIOR, O.A.; GUIMARÃES, R.F.; GOMES, R.A.T.; MARTINS, E.S.; GOMES-LOEBMANN, D. Determinação do potencial de erosão a partir da utilização da EUPS na bacia do Rio Preto. Espaço e Geografia, 10:431$452,2007$.

GABOARDI, C. Generalização E Análise Multirresolução De Modelos Digitais Do Terreno Com Base Em Transformada Wavelet. 2009. 158 F. Tese (Doutorado Em Ciências Geodésicas) - Setor de Ciências da Terra da Universidade Federal do Paraná, 2009.

GRECU, F. Geomorphological Map of the Prahova Subcarpathians (Romania). Journal of Maps, p. 108-116, 2009. https://doi.org/10.4113/jom.2009.1052

GUERRA, A. T.; GUERRA, A. J. T. Novo Dicionário Geológico-geomorfológico. 6. ed. Rio de Janeiro: Bertrand Brasil, 2008.

GUSTAVSSON, M. Development of a Detailed Geomorphological Mapping System and GIS Geodatabase in Sweden. Acta Universitatis Upsaliensis. Digital Comprehensive Summaries of Uppsala Dissertations from the Faculty of Science and Technology 236. Uppsala. 36 p, 2006.

HENGL, T.; EVANS, I. S. Mathematical and digital models of the land surface. In: HENGL, T.; REUTER, H. I. (Org.). Geomorphometry: concepts, software, applications. Developments in Soil Science, vol. 33. Amsterdam: Elsevier, 2009. p. 31-63. https://doi.org/10.1016/S0166-2481(08)00002-0

HUTCHINSON, M.F. A new procedure for gridding elevation and stream line data with automatic removal of spurious pits. Journal of Hydrology, 106, p. 211-27, 1989. https://doi. org/10.1016/0022-1694(89)90073-5

LOPES, F.C.A.; SANTOS, I. Uma Nova Metodologia
Para Elaboração De Modelos Digitais Hidrologicamente Consistentes. In: XIII SIMPÓSIO BRASILEIRO DE GEOGRAFIA FÍSICA APLICADA, Viçosa, 2009. p. 1-14.

MACMILLAN, R. A.; SHARY, P. A. Landforms and Landform Elements in Geomorphometry. HENGL, T.; REUTER, H. I. Geomorphometry: concepts, software, applications. Developments ion Soil Science, vol. 33, Hungary: ELSEVIER, 2009, p. 227-254.

MARTINS, T. I. S.; RODRIGUES, S. C. Compartimentação Geomorfológica da Folha Piumhi,Região do Alto São Francisco, Minas Gerais. Revista Brasileira de Geomorfologia (Online), São Paulo, v.17, n.1, Jan-Mar, p.145-162, 2016. http://dx.doi. org/10.20502/rbg.v17i1.873

MEDEIROS, A. Introdução aos Mapas de Kernel. Disponível em: < http://www.andersonmedeiros.com/mapas-de-kernelparte-1/>. Acesso em set. 2016.

MMA/IBAMA. Plano de Manejo da Serra da Canastra. 2005. Disponível em: <http://www.icmbio.gov.br/portal/images/ stories/imgs-unidades coservacao /PM _PNSC_Resumo_ Executivo.PDF>. Acesso em: 20 mai. 2012.

NAZAR, T.I.S.M. O Chapadão do Diamante na Serra da Canastra/MG, Brasil: caracterização geomorfológica e análise integrada do meio físico a partir de dados multifontes. 2018. 270 f. Tese (Doutorado em Geografia) - Universidade Federal de Uberlândia, Uberlândia, 2018. http://dx.doi. org/10.14393/ufu.te.2018.608

OLAYA, V. Basic Land-surface Parameters. In: HENGL, T.; REUTER, H. I. Geomorphometry: concepts, software, applications. Developments ion Soil Science, vol. 33, Hungary: ELSEVIER, 2009, p. 141-171. https://doi.org/10.1016/S01662481(08)00006-8

PAVLOPOULOS, K.; EVELPIDOU, N.; VASSILOPOULOS, A. Mapping geomorphological Environments. Berlin: Springer, 2009. https://doi.org/10.1007/978-3-642-01950-0

PIKE, R. J.; EVANS, I. S.; HENGL, T. Geomorphometry: a brief guide. In: HENGL, T.; REUTER, H. I. (Org.). Geomorphometry: concepts, software, applications. Developments in Soil Science, vol. 33. Amsterdam: Elsevier, 2009. p. 3-30. https://doi. org/10.1016/S0166-2481(08)00001-9

REDIVO, A.L.; GUIMARÃES, R.F.; RAMOS, V.M.; CARVALHO JÚNIOR, O.A.; MARTINS, E.S. Comparação entre diferentes interpoladores na delimitação de bacias hidrográficas. Planaltina, Embrapa Cerrados, 2002. 20p. 
ROSA, R.; BRITO, J. L. S. Introdução ao geoprocessamento: sistema de informação geográfica. Uberlândia: EDUFU, 1996.

ROSS, J. L. S. Geomorfologia: ambiente e planejamento. 8 ed. São Paulo: Contexto, 2007.

ROSS, J. L. S. O registro cartográfico dos fatos geomorfológicos e a questão da taxonomia do relevo. Revista do Departamento de Geografia, n.6, São Paulo: Edusp, p. 17-30, 1992.

SAMPAiO, T. V. M.; AUGUSTIN, C. H. R. R. Índice de Concentração da Rugosidade: uma Nova Proposta Metodológica Para o Mapeamento e Quantificação da Dissecação do Relevo como Subsídio a Cartografia Geomorfológica. Revista Brasileira de Geomorfologia, São Paulo, v.15, n.1, (Jan-Mar) p.47-60, 2014. http://dx.doi. org/10.20502/rbg.v15i1.376

SANTOS, L. J. C.; OKA-FIORI, C.; CANALI, N. E.; FIORI, A. P.; SILVEIRA, C. T.; SILVA, J. M. F.; ROSS, L. S. R. Mapeamento Geomorfológico do Estado do Paraná. Revista Brasileira de Geomorfologia, São Paulo, v.7, n.2, p. 3-12, 2006. http://dx.doi.org/10.20502/rbg.v7i2.74

SCHMIDT, J., HEWITT, A., Fuzzy land element classification from DTMs based on geometry and terrain position. Geoderma, 121 (3-4), p. 243-256, 2004. https://doi.org/10.1016/j. geoderma.2003.10.008

SILVA, T. I.; RODRIGUES, S. C. Elaboração de um Tutorial de Cartografia Geomorfológica como Alternativa para o Ensino de Geomorfologia. Revista Geográfica Acadêmica, v. 3, p. 85-94, 2009. https://revista.ufrr.br/rga/issue/viewIssue/179/6

SILVA, T.I.; RODRIGUES, S.C. A utilização de SIGs e técnicas de Geoprocessamento a partir de imagens da SRTM para a Compartimentação Geomorfológica da Bacia do Médio-Baixo Curso do Rio Araguari/MG. Caderno de Geografia (PUCMG. Impresso), v. 20, p. 58-73, 2010. http://periodicos.pucminas.br/ index.php/geografia/article/view/1684/1913

SILVEIRA, R.M.P.; SILVEIRA, C.T. Análise Digital do Relevo Aplicada à Cartografia Geomorfológica da Porção Central da Serra do Mar Paranaense. Revista Brasileira de Geomorfologia, São Paulo, v.17, n.4, (Out-Dez) p.615-629, 2016. http://dx.doi.org/10.20502/rbg.v17i4.1063
SIMÕES, L.S.A.; MARTINS, J.E.S.; VALERIANO, C.M.; GODOY, A. M.; ARTUR, A. C. Folha Vargem Bonita, SF.23-VB-I. Projeto Fronteiras de Minas Gerais. Programa Mapeamento Geológico do Estado de Minas Gerais. Contrato CODEMIG 3473, FUNDEP 19967. UFMG: 2015.

SENA-SOUZA, J.P.; CARVALHO JUNIOR, O.A.; MARTINS, E.S. VASCONCELOS, V., COUTO JUNIOR, A.F.; GOMES, R.A.T; GUIMARÃES, R.F. Comparação dos Métodos de Classificação por Ângulo Espectral e Distância Euclidiana no Mapeamento das Formas de Terreno. Revista Brasileira de Geomorfologia, São Paulo, v.17, n.3, (Jul-Set) p.591-613, 2016. http://dx.doi.org/10.20502/rbg.v17i3.846

SOUZA, D. A.; RODRIGUES, S. C. Aspectos Morfoestruturais e Morfoesculturais da Serra da Canastra e Entorno (MG). Revista do Departamento de Geografia - USP, v. 27, p. 47-66, 2014. UHLEIN, A.; FONSECA, M. A.; SEER, H. J.; DARDENE, M. A. Tectônica da Faixa de Dobramentos Brasília - setores sententrional e meridional. Geonomos, Belo Horizonte, v. 20, n. 2, p. 1-14, 2012.

VALERIANO, M. M. Curvatura vertical de vertentes em microbacias pela análise de modelos digitais de elevação. Revista Brasileira de Engenharia Agrícola e Ambiental, v.7, n.3, p.539-546, 2003.

VALERIANO, C. M.; DARDENE, M. A.; FONSECA, M. A.; SIMÕES, L. S. A.; SEER, H. J. A evolução tectônica da Faixa Brasília. In: MANTESSO-NETO, V. et al. (Org.). Geologia do continente sul-americano: evolução da obra de Fernando Flávio Marques de Almeida. São Paulo: Beca, 2004. p. 575-592.

VOZENÍLEK, V. Integration Gis and GPS within Geomorphological Mapping. In: $21^{\text {st }}$ INTERNATIONAL CARTOGRAPHIC CONFERENCE (ICC), 2003, Durban. Proceedings... Durban, South Africa, 10-16 August 2003. p. 1956-1967.

WEISS, A. D. Topographic Positions and Landforms Analysis. Conference Poster. In: ESRI INTERNATIONAL USER CONFERENCE, San Diego, CA, p. 9-13. 2001. Disponível em: < http://www.jennessent.com/downloads/tpiposter-tnc_18x22.pdf $>$.Acesso em set. 2016. 